\title{
WestVirginiaUniversity
}

THE RESEARCH REPOSITORY @ WVU

Graduate Theses, Dissertations, and Problem Reports

2000

\section{Corrosion between orthodontic archwires and bracket couples}

Brian Costello O'Leary

West Virginia University

Follow this and additional works at: https://researchrepository.wvu.edu/etd

\section{Recommended Citation}

O'Leary, Brian Costello, "Corrosion between orthodontic archwires and bracket couples" (2000). Graduate Theses, Dissertations, and Problem Reports. 1092.

https://researchrepository.wvu.edu/etd/1092

This Thesis is protected by copyright and/or related rights. It has been brought to you by the The Research Repository @ WVU with permission from the rights-holder(s). You are free to use this Thesis in any way that is permitted by the copyright and related rights legislation that applies to your use. For other uses you must obtain permission from the rights-holder(s) directly, unless additional rights are indicated by a Creative Commons license in the record and/ or on the work itself. This Thesis has been accepted for inclusion in WVU Graduate Theses, Dissertations, and Problem Reports collection by an authorized administrator of The Research Repository @ WVU. For more information, please contact researchrepository@mail.wvu.edu. 


\title{
CORROSION BETWEEN ORTHODONTIC ARCHWIRES
} AND BRACKET COUPLES

\author{
Brian C. O'Leary, D.M.D.
}

Thesis submitted to the

School of Dentistry At West Virginia University in partial fulfillment of the requirements for the degree of

\section{MASTER OF SCIENCE \\ in \\ Orthodontics}

\author{
Michael Bagby, DDS, PhD, Chair \\ Marcia Gladwin, RDH, EdD \\ Kavita Kohli, BDS, DDS \\ Department of Orthodontics
}

\author{
West Virginia University \\ Morgantown, West Virginia \\ 2000
}

Keywords: Corrosion, Orthodontics, Galvanic coupling 


\title{
ABSTRACT \\ CORROSION BETWEEN ORTHODONTIC ARCHWIRES AND BRACKET COUPLES
}

\author{
Brian C. O'Leary, D.M.D.
}

Nickel-containing orthodontic wires have been reported to cause allergic reactions in sensitive individuals. However, stainless steel brackets also contain nickel and could potentially elicit a reaction. The ability of these metals to cause an allergic reaction is related to corrosion of the alloys and subsequent leaching of nickel ions into the oral cavity. The purpose of this study was to determine if there is a significant difference in the corrosive potential of stainless steel, NiTi and TMA wires either alone or when coupled with a stainless steel bracket.

At least two wires and bracket/wire combinations of each type were tested using potentiostatic anodic polarization. The samples were tested in $0.9 \% \mathrm{NaCl}$ solution at room temperature with neutral $\mathrm{pH}$. Using a Wenking MP 95 potentiostat, the breakdown potential for each sample was determined from constructed polarization curves. The potentiostat was connected to an electrochemical corrosion cell and data was collected using a computer and data acquisition program. The samples were visually analyzed for surface changes and photographs were taken.

The breakdown potentials of stainless steel ("A" Co.), NiTi (Ormco), TMA (Ormco), and the stainless steel bracket (Ormco) were $600 \mathrm{mv}, 1600 \mathrm{mv},>2000 \mathrm{mv}$, and $200 \mathrm{mv}$ respectively. When coupled with a stainless steel bracket, the breakdown potential for all three of the wire types was $200 \mathrm{mv}$. The breakdown potential of the stainless steel bracket overrode the potential for the wires themselves and the samples all broke down at the point where the bracket would have corroded by itself. The stainless steel brackets proved to be the weak ling in the galvanic couple with the three wire types and the brackets have a significantly higher corrosive potential than any of the wires themselves.

If a patient has a nickel allergy, the orthodontist would be wise to avoid the use of stainless steel brackets in addition to nickel containing archwires. TMA wires do not contain nickel and they have a very high resistance to corrosion. TMA wires would be an acceptable substitute for NiTi while ceramic brackets should be considered instead of stainless steel. 
To my parents, John and Mary Ellen, whose love, support and example have allowed me to pursue all of my goals in life. 


\section{ACKNOWLEDGEMENTS}

My sincere appreciation to the following individuals:

Dr. Michael Bagby for serving as my chairman and helping me complete this project.

Dr. Marcia Gladwin for her encouragement and serving on my committee.

Dr. Peter Ngan for his commitment to excellence and his dedication to education for his residents.

Dr. Hera Kim for her help and support throughout the course of this study.

Dr. Kavita Kohli for her willingness to serve on my committee in Dr. Ngan's absence.

My fellow residents for their friendship and the memorable times we have had together.

Dr. Edward Mah for his computer expertise.

Ormco Corp. for supplying brackets and wires for the project.

3M Unitek for supplying the gold wires and their help in the completion of the project. 


\section{TABLE OF CONTENTS}

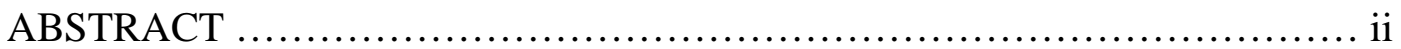

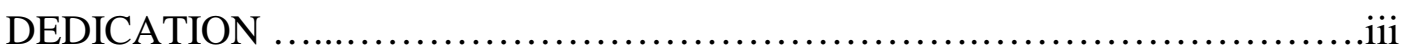

ACKNOWLEDGEMENTS ................................................... iv

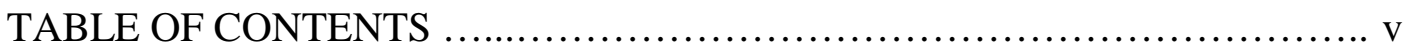

LIST OF FIGURES ......................................................

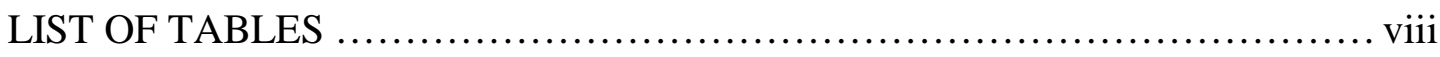

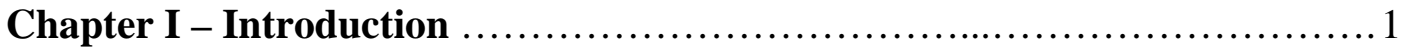

Background ...................................................... 1

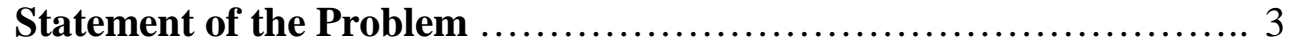

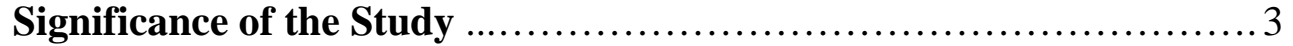

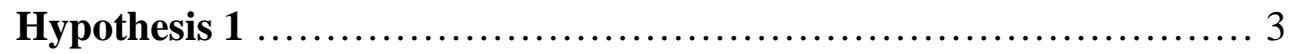

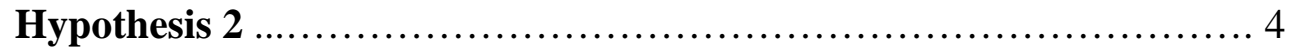

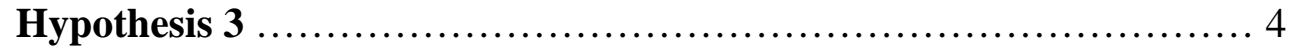

Specific Aims .................................................... 4

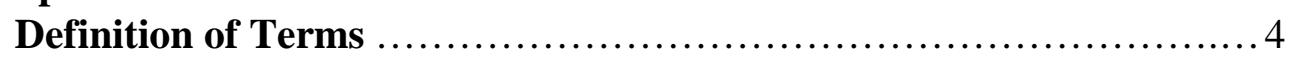

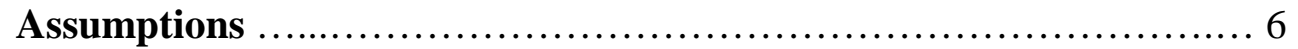

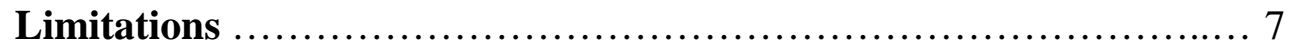

Delimitations ........................................................ 7

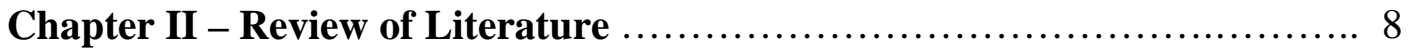

Chapter III - Methods and Materials ...................................... 19

Sample Description ............................................. 19

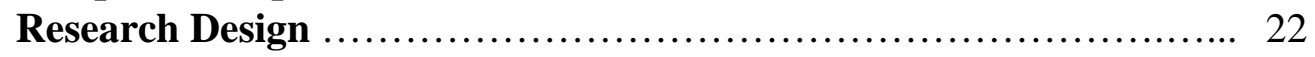

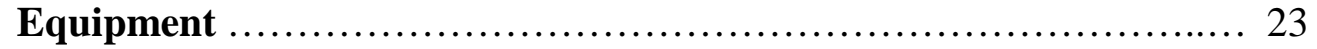

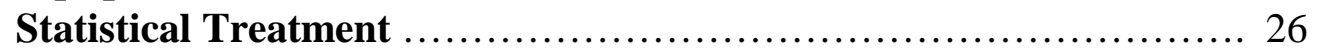

Chapter IV - Results and Discussion ................................... 28

Chapter V - Summary and Conclusions ................................. 43

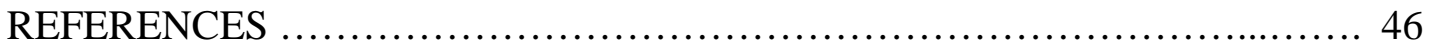




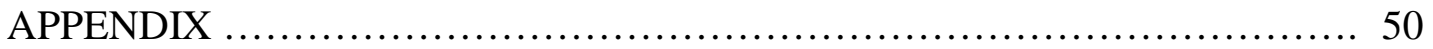

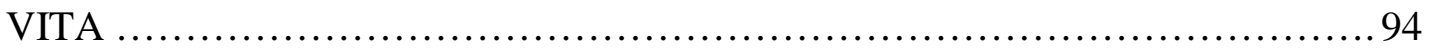




\section{LIST OF FIGURES}

Figure 1: $\quad$ Photograph of Wenking MP 95 potentiostat $\ldots \ldots \ldots \ldots \ldots \ldots \ldots \ldots . \ldots 24$

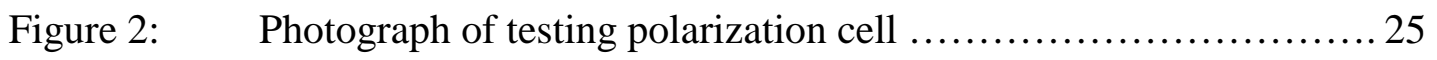

Figure 3: $\quad$ Photograph of stainless steel bracket after testing (frontal view)............................................. 29

Figure 4: $\quad$ Photograph of stainless steel bracket after testing

(lateral view)

Figure 5: Potentiostatic anodic polarization curve for stainless

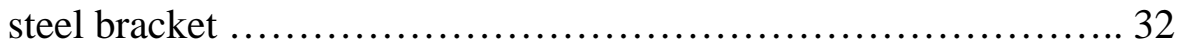

Figure 6: $\quad$ Potentiostatic anodic polarization curve for stainless steel wire ..................................................... 33

Figure 7: $\quad$ Potentiostatic anodic polarization curve for NiTi wire .............33

Figure 8: $\quad$ Potentiostatic anodic polarization curve for TMA wire ............. 34

Figure 9: $\quad$ Potentiostatic anodic polarization curve for stainless steel wire and stainless steel bracket combination ..................... 34

Figure 10: $\quad$ Potentiostatic anodic polarization curve for NiTi wire and stainless steel bracket combination ............................ 35

Figure 11: Potentiostatic anodic polarization curve for TMA wire and stainless steel bracket combination

Figure 12: $\quad$ Potentiostatic anodic polarization curve for stainless steel wire and ceramic bracket combination ....................... 36

Figure 13: Potentiostatic anodic polarization curve for gold-coated stainless steel wire

Figure 14: Potentiostatic anodic polarization curve for "scratched" gold-coated stainless steel wire 


\section{LIST OF TABLES}

Table 1: $\quad$ Percentage by weight of element compositions of samples ........ 20

Table 2: $\quad$ Breakdown potentials of individual samples ..................... 27

Table 3: $\quad$ Breakdown potentials of coupled samples ....................... 30 


\section{CHAPTER I \\ INTRODUCTION}

\section{BACKGROUND}

Orthodontic wires containing nickel have been implicated in allergic reactions. Nickel has been shown to be an allergen in certain individuals. ${ }^{1}$ Sources that may provide nickel exposure include jewelry, food, environmental, occupational, and dental alloys. $^{2-14}$ With increased exposure to nickel comes a greater likelihood of developing an allergy. Individuals may become sensitized to nickel, which may lead to a subsequent allergic reaction. ${ }^{2-14}$ In the field of dentistry, nickel containing alloys are commonly used. Recently, in orthodontics, with the advent of nickel-titanium wires,

nickel-containing alloys are utilized much more frequently. ${ }^{15}$ Introduced as Nitinol in the late 1970's and popularized as NiTi in the late 1980's, these "superelastic" archwires have become almost a standard element of the orthodontist's armamentarium. Stainless steel brackets and wires have been used for over a century in orthodontics and contain approximately $8 \%$ nickel. Case studies report hypersensitivity reactions to nickel, stimulated by the exposure to stainless steel orthodontic brackets. ${ }^{12}$

All metals will corrode in the proper environment. Nickel can be made available from alloys through leaching and corrosion. ${ }^{9}$ The corroding of the metal is evidenced by surface changes such as discoloration and pitting. ${ }^{16,17}$ After corrosion testing, the solution can be analyzed for the presence of ions. ${ }^{18-20}$ The most common 
form of corrosion testing is called potentiostatic anodic polarization. This technique has been used for years to study the corrosive behavior of metals. ${ }^{21-34}$ The test is electrochemical in nature and can determine when a sample has passed from a passive to an active state. This correlates with the breakdown of the passive layer and when corrosion of the sample begins.

Corrosion of biomaterials may release nickel to be absorbed by the body. The prolonged exposure to nickel alloys may lead to a sensitization to nickel. The ability of orthodontic brackets and wires to cause an allergic reaction is related to the pattern and mode of corrosion with subsequent release of nickel into the oral cavity. When unlike metals are placed in the same environment, a galvanic couple is created. Coupled corrosion may differ greatly from corrosion of an individual metal. When two dissimilar metals are in contact with each other, the more noble metal will behave in a cathodic manner. ${ }^{35}$ The less noble metal in a coupled system will become the anode and corrode at an accelerated rate. Orthodontic treatment commonly employs the use of dissimilar metallic components in the same appliance. The corrosion resistance of stainless steel and other orthodontic metals is relatively good. However, these metal alloys are challenged by the hostile environment in the mouth, and are susceptible to localized corrosion in a low $\mathrm{pH}$ environment containing chloride ions. ${ }^{35}$ Archwires and brackets used in orthodontics are commonly made of many different alloys. The corrosive potential that exists between archwires and brackets of various metal compositions has not been thoroughly investigated. 


\section{STATEMENT OF THE PROBLEM}

Do nickel titanium (NiTi) archwires have a higher corrosive potential than stainless steel or titanium molybdenum alloy (TMA) wires when coupled with a stainless steel orthodontic bracket?

\section{SIGNIFICANCE OF THE STUDY}

Wires and appliances that contain nickel are used routinely in the practice of orthodontics. Nickel-titanium archwires and expansion appliances have an especially high content of nickel. Corrosion of these alloys releases nickel into the oral cavity and may contribute to the development of a nickel allergy or elicit an allergic response in certain predisposed individuals. The combination of archwires and stainless steel brackets produces a galvanic couple, which may enhance the corrosive potential of the dissimilar metals and could have very different corrosive characteristics than the single metal. By determining the corrosive potentials of commonly coupled orthodontic alloys, the clinician may be better prepared to select which brackets and archwires to use to avoid potential nickel allergy problems in particular patients.

\section{HYPOTHESIS 1}

There is a significant difference in the corrosive potential of stainless steel, $\mathrm{NiTi}$, and TMA orthodontic archwires when tested using potentiostatic anodic polarization testing. 


\section{HYPOTHESIS 2}

There is a significant difference in the corrosive potential of stainless steel,

$\mathrm{NiTi}$, and TMA orthodontic archwires when galvanically coupled with a stainless steel bracket using potentiostatic anodic polarization testing.

\section{HYPOTHESIS 3}

There is a significant difference in the corrosive potential of stainless steel, NiTi, and TMA orthodontic archwires when galvanically coupled with a stainless steel bracket versus the corrosive potential of the wire or bracket alone using potentiostatic anodic polarization testing.

\section{SPECIFIC AIMS}

The specific aims of this study are to:

1. Compare the breakdown potentials of stainless steel, NiTi, and TMA orthodontic archwires.

2. Compare the corrosive breakdown potential of stainless steel, NiTi, and TMA orthodontic archwires when galvanically coupled with a 0.22 " slotted stainless steel bracket.

\section{DEFINITION OF TERMS}

Anode--the electrode of an electrolytic cell where oxidation occurs. Electrons flow away from the anode in an electric circuit. 
Anodic dissolution--the transfer of metal ions into solution from the anode of an electrochemical cell when a potential is applied.

Anodic polarization--the change of the electrode potential in the positive or noble direction due to current flow.

Auxiliary or counter electrode--the electrode in an electrochemical cell that is used to transfer current to or from a test electrode. (Usually platinum)

Breakdown potential--the least noble potential where pitting, crevice corrosion, or both will initiate and propagate releasing metal ions. Characterized by a significant increase in current.

Cathode--the electrode of an electrochemical cell where reduction occurs.

Corrosion--the chemical or electrochemical reaction between a material, usually a metal, and its environment that produces a deterioration of the material and its properties.

Crevice corrosion--localized corrosion of a metal surface, at or immediately adjacent to, an area that is shielded from full exposure to environment because of close proximity between the metal and the surface of another material.

Current density--the electric current to or from a unit area of an electrode surface units are typically $\mathrm{mA} / \mathrm{mm}^{2}$.

Electrochemical cell--an electrochemical system consisting of an anode and a cathode in metallic contact and immersed in an electrolyte.

External circuit--the wires, connectors, measuring devices, current sources, etc. that are used to bring about or measure the desired electrochemical conditions within the test cell. 
Galvanic couple--a pair of dissimilar conductors, commonly metals in electric contact. Internal Circuit--the working, counter, and reference electrodes immersed in the electrolyte.

Pitting--corrosion of a metal surface, confined to a point or small area, that takes the form of cavities.

Potentiostat--an instrument for automatically maintaining an electrode in an electrolyte at a constant potential or controlled potentials with respect to a suitable reference electrode.

Reference electrode--usually a saturated calomel electrode used as the reference potential of an electrochemical cell.

Working electrode--the test or specimen electrode in an electrochemical cell.

\section{ASSUMPTIONS}

Three assumptions form the basis of this study. The first is that the breakdown potential for the bracket, wires and combinations can be reached using potentiostatic anodic polarization testing. The second is that the wire and bracket combinations are consistent in their imperfections from one combination to another. Finally, the results of anodic polarization provide data relevant to corrosion of biomaterials.

\section{LIMITATIONS}

1. The environment of the oral cavity cannot be accurately duplicated in an in vitro study of this nature. 
2. The corrosive potentials may fluctuate with changes in $\mathrm{pH}$, temperature, percentage oxygen $\left(\mathrm{pO}_{2}\right)$, and percentage carbon dioxide $\left(\mathrm{pCO}_{2}\right)$.

\section{DELIMITATIONS}

1. A limited number of bracket and archwire combinations will be studied.

2. The testing solution will not be oxygenated.

3. The testing conditions will be maintained at neutral $\mathrm{pH}$ and room temperature. 


\section{CHAPTER II}

\section{REVIEW OF LITERATURE}

Nickel can be found in all parts of the world and is the $24^{\text {th }}$ most abundant element in the earth's crust. ${ }^{2}$ Allergies to nickel are commonly seen and are more prevalent in women, causing allergic contact dermatitis. ${ }^{1}$ Female predilection can be explained by the use of jewelry and in particular inexpensive costume jewelry. In the United States, the reported prevalence of nickel sensitivity ranges from $9.5 \%-31.9 \%$

in females and $2 \%-20.7 \%$ in males. ${ }^{3-5,14,19}$ However in countries such as Nigeria, the prevalence of nickel allergies is equal between the sexes as a result of equal wearing of jewelry. $^{7}$

The contact dermititis that results from a nickel allergy was originally associated with workers in the nickel industry and was referred to as "nickel itch". Clinical presentation was characterized by an itching or burning papular erythema. Another presentation is a papular or papulovesicular dermatitis with a propensity for lichenification. ${ }^{8}$

Allergies have appeared in dentistry and related fields with the use of nickel containing alloys and are sometimes associated with the oral lesions of lichen planus. ${ }^{10}$ An allergic reaction to nickel-titanium orthodontic wire was reported in the late 1980's. ${ }^{12}$ The patient reported a history of allergic reactions to jewelry and responded to the alloy after only a few days. The patient complained of a burning sensation of the 
oral mucosa and developed painful lesions within one month. Large erythematous macular lesions were seen throughout the mouth. After removal of the NiTi wire, complete healing occurred within four days.

It has been shown that the ability of a metal to cause an allergic reaction is related to the process of corrosion. Corrosion is seen in all base metals and is relatively high in nickel alloys. ${ }^{9}$ When a nickel containing alloy corrodes it leaches nickel and may cause an allergic reaction in certain individuals. ${ }^{8}$

Corrosion is a very complex process that results in the deterioration of a metal by its reaction with the environment. The oral cavity is conducive to electrochemical or electrolytic corrosion due to its moisture content. ${ }^{35}$ When a metal is placed in an aqueous solution it will be thermodynamically unstable if the tendency to pass from a solid state to an ionic form is associated with a decrease in energy. This direction of energy change can be influenced by many factors. They include: the metal, the surface morphology of the metal, composition of the solution, $\mathrm{pH}$, temperature and other metals in the environment. As with all things in nature, equilibrium will attempt to be reached, by decreasing the energy of the system. The process will continue until this equilibrium is reached or the release of ions is prevented. A passivating film that coats a metal surface will prevent the metal from contacting the solution. ${ }^{36-41}$ When ions are not released, then corrosion does not occur.

Corrosion testing can be performed in several ways. Simple observation of surface characteristics, such as pitting may be done using various forms of microscopy. ${ }^{16-17}$ Another method to evaluate corrosion is to analyze the material and solution in which a corrosive potential has been created. ${ }^{18-20}$ The standard testing 
technique uses a potentiostatic anodic polarization (PAP) device. P.A.P. has become the benchmark for measuring the corrosive behavior of metals. ${ }^{21-34}$ P.A.P. techniques are the most commonly used electrochemical methods for quantifying corrosive characteristics of a metal. P.A.P. applies a potential to produce corrosion of a test sample. Polarization measurement using potentiostatic techniques have been shown to be valuable in characterizing, and quantifying active-passive systems. P.A.P techniques are able to detect the transition of a system from a passive state to an active state, or in other words, when corrosion begins. ${ }^{31}$ The potentiostat is notable in that it maintains a constant potential of a specimen at a desired level by automatically altering the current flowing between the working electrode and a counter electrode to maintain the desired potential or voltage. ${ }^{33}$ Initially, when the applied potential is low, the current is low. The current and voltage are recorded. The voltage is increased over time until the potential is sufficiently high to break down the passive layer and significantly increase the current. This is referred to as the "critical" or "breakdown" potential, and is typically accompanied by a release of oxygen from the surface film. With the data obtained, a potentiostatic polarization curve can be plotted and the breakdown potential can be determined.

Rostoker et al. ${ }^{16}$ attempted to quantify surface irregularities by observing the surface of the metals using optical microscopy before and after testing. The samples were submerged in $1 \%$ saline solution at 37 degrees centigrade for up to 100 days without the use of applied potential. The samples were designed to simulate galvanic coupling and crevice conditions. The results of the study showed that no corrosion was visible on the Ti-6A1-4V when uncoupled, coupled with itself, or coupled with 
316L stainless steel, cast Co-Cr-Mo, or graphite. In contrast, 316L stainless steel exhibited multiple areas of pitting in all tests. These results imply that the principles of galvanic corrosion apply and the lesser noble metal will have an increased corrosion potential.

A comparison study was performed by Edie et al. ${ }^{17}$ to demonstrate the surface corrosion characteristics of nitinol and stainless steel orthodontic archwires after intraoral use and subsequent exposure to anodic dissolution. In this study, only the nitinol wires were subjected to anodic dissolution. The sample consisted of eleven nitinol and eleven stainless steel wires after being in clinical use from one to eight months. The used wires, unused portions of nitinol and stainless steel wires, and nitinol wires which had been subjected to anodic dissolution for two minutes, were mounted for SEM observation. The results of the study demonstrated that unused nitinol wire showed large variations in surface texture when compared to stainless steel. SEM studies showed no discernible differences in surface morphology between nitinol wires before and after anodic dissolution. No pits were observed on either nitinol or stainless steel wires after clinical use. The conclusion was drawn that there was no evidence to support that nitinol wires have a higher corrosive potential than stainless steel wires. Other authors state that nitinol is more prone to corrosion than stainless steel. ${ }^{22}$

To test the effects of corrosion on mechanical properties, Harris et al. ${ }^{43}$ attempted to simulate the oral environment by submerging nitinol wires in buffered solutions of $1 \% \mathrm{NaCl}$ at $\mathrm{pH} 3, \mathrm{pH} 5$, and $\mathrm{pH}$ 7. Straight sections of 0.016 " nitinol wire were used in templates that deflected the wires $0,1,2$, and $4 \mathrm{~mm}$. Twelve samples were 
tested initially with four lengths of wire placed on each template. The templates were incubated in the solutions for 1,2, and 4 months at 37 degrees $\mathrm{C}$ and tested at these intervals. The nickel content of the test solutions was not reported. Wires were placed in an Instron unit and tested for ultimate stress, ultimate strain, modulus of elasticity, and $0.3 \%$ yield strength. The results of the study showed that for the wires incubated in solution, there was a $10 \%$ reduction in $0.2 \%$ yield strength and a significant reduction in ultimate stress and modulus of elasticity. The magnitude of decrease was comparable to other studies which exposed wires to solutions of differing $\mathrm{pH}$ or amount of deflection. ${ }^{42-43}$ It has been shown that the $\mathrm{pH}$ in plaque can be as low as 4 and salivary $\mathrm{pH}$ can be as high as 9 .

Grimsdottir et al. measured the amount of nickel and chromium released from individual orthodontic appliances when submerged in a $.9 \% \mathrm{NaCl}$ solution for 14 days. The testing sample consisted of five sections of common face-bows along with five molar bands, brackets and archwires. The section of the face-bow was taken from the portion where the outer bow and inner bow were soldered together. The face-bow and wire samples were then cut to approximate the area ratio of a molar band. The samples were separately placed in $1 \mathrm{ml}$ of $0.9 \% \mathrm{NaCl}$ solution and incubated for 7 days at 23 degrees $\mathrm{C}$. At this point, the samples were then placed into a fresh solution and the process was completed at 14 days. The solutions were then analyzed for $\mathrm{Ni}$ and $\mathrm{Cr}$ content using flameless atomic absorption spectrophotometry. Negligible amounts of nickel and chromium were released from the archwires while the largest amounts were released from the face-bows, particularly GAC's (10.4micrograms Ni and 13.9 micrograms $\mathrm{Cr}$ ). The increased amount from the face-bows was explained by the 
inclusion of the solder joint. The silver solder and stainless steel wire created a galvanic couple, reducing corrosion resistance. ${ }^{19}$

Corrosion can theoretically have a large impact on the mechanical properties of a metal. Schwaninger et al. and Harris et al. attempted to study the effects of corrosion on the physical properties of a nitinol archwire. ${ }^{42,43}$ Schwaninger used $1 \% \mathrm{NaCl}$ solution to recreate the recommended conditions of Sarkar's report that Ringer's solution adequately represents the corrosive nature of saliva in conjunction with potentiostatic anodic polarization..$^{20}$ The sample consisted of sixty 0.016 " nitinol wires. The samples were divided into six groups of ten wires each. The control group consisted of one-inch spans removed from each wire. The remaining wires were then incubated at 37 degrees $\mathrm{C}$. The wire samples were removed every two months after the first month for a total period of 11 months. After completion, five wires were tested for flexural yield and modulus of stiffness. Five wires were subjected to 90degree bend cycles to fatigue the wire. The control samples were also tested. SEM observation was then used to analyze the fractured surfaces of the fatigued wires to determine the mode of failure. The results showed no significant difference in physical properties of nitinol wire after in vitro corrosion of eleven months. The conclusion was drawn that the early failure of the wire was due to the presence of surface defects generated during the manufacturing process and not due to corrosion effects. The nickel content of the solutions was not reported in the study.

Kerosuo et al. ${ }^{20}$ studied $\mathrm{Ni}$ and $\mathrm{Cr}$ release from orthodontic appliances using static and dynamic conditions. The orthodontic appliances used were a face-bow, a quad-helix and fixed appliances. A simulated dental quadrant was constructed from 
central incisor to first molar. Fixed appliances were placed using a first molar band and brackets on the second premolar to the central incisor. A 0.014 " NiTi wire was tied to the brackets using stainless steel ligatures. The inside surface of the band and the bracket bases were covered with cold cure acrylic. The quad-helix was constructed of 0.036 " stainless steel wire soldered to a molar band and the wire was cut to use only half of the appliance. Once again, only half of the face-bow was used and it consisted of half of the inner bow and a molar band. Five samples of each appliance were tested under static conditions and each appliance was placed in $15 \mathrm{ml}$ of $0.9 \% \mathrm{NaCl}$ solution and incubated at room temperature for 2 hours, 24 hours and 7 days. After each time interval, the samples were removed and placed in a fresh $\mathrm{NaCl}$ solution. The testing solution was then analyzed for $\mathrm{Ni}$ and $\mathrm{Cr}$ content using flameless atomic absorption spectrophotometry. For the fixed appliances placed on the dental quadrant, an "oral functioning simulator" was constructed to study the effects of movement on corrosion. The sample quadrant was alternated between movement and rest every other hour. The results of the static test showed that only the quad helix had significant amounts of $\mathrm{Ni}$ release during the first two hours. At 24 hours and 7 days, significantly less Ni was released from the quad-helix than from the fixed appliances or the face-bow. The amount of Ni released in 7 days from the fixed appliances under dynamic conditions was significantly higher than those in the static state. The amount of $\mathrm{Cr}$ released in 7 days was significantly lower and there was no significant difference in the $\mathrm{Cr}$ release between static and dynamic conditions. ${ }^{20}$

Sarkar et al. performed a study to compare the corrosion byproducts of amalgam subjected to potentiostatic anodic polarization and corrosion byproducts of 
forty year-old amalgam which had been in service intraorally. The fresh amalgam sample was tested in Ringer's solution using potentiostatic anodic polarization. The experiment demonstrated that the corrosion byproducts of the two amalgam samples were very closely matched. ${ }^{21}$

Park et al. ${ }^{18}$ studied the corrosion effect of a simulated intraoral environment on orthodontic appliances and the release of nickel and chromium. A solution of $0.05 \% \mathrm{NaCl}$ was used. Incubated bands and brackets that would be used on a quadrant of the mandibular arch were tested. Ten simulated orthodontic appliances were constructed using brackets for the canine and incisors, first and second premolar bands, and first and second molar bands. The bracket bases and internal surfaces of the bands were covered with cold cure acrylic resin. The bands and brackets were attached to an 0.019 " x 0.025 " x 2.8 " stainless steel wire with elastomeric ties. Each of the samples was placed in its own poplyethelene bottle filled with the $\mathrm{NaCl}$ solution and incubated at 37 degrees Celsius. Samples of $4 \mathrm{ml}$ were taken from each solution bottle on days $3,6,9$, and 12 and the same amount of fresh solution was replaced. Using flameless atomic absorption spectrophotometry, the solution was tested for nickel and chromium content. At the completion of the 12 days, the precipitate from each bottle was collected by centrifugation and washed three times with $0.5 \% \mathrm{NaCl}$ solution. The precipitate was dried overnight at 85 degrees Celsius and solubilized in nitric acid to enable testing. The results showed that three times more nickel than chromium was solubilized. After 12 days of testing the total amounts of soluble nickel and chromium were 121 micrograms and 40 micrograms respectively. The resulting average daily 
release was 40 micrograms of nickel and 36 micrograms of chromium. No NiTi wires were used in this experiment. ${ }^{18}$

Products have been manufactured which minimize the corrosive potentials of alloys commonly employed by the orthodontist. Nickel-titanium wires have been manufactured with nitride and epoxy coatings. Nitride coatings are used in orthodontics to increase the hardness of the archwire, while epoxy coatings provide an esthetic alternative to the standard orthodontic wires. The addition of these coatings may provide some form of corrosion resistance as an added benefit. Kim and Johnson $^{44}$ used potentiostatic anodic polarization to test the corrosive potential of various archwires. Corrosion occurred readily in stainless steel and in some nickeltitanium wires. The breakdown potential of nickel-titanium wires seemed to vary between manufacturers. Nitride coating did not affect the corrosion of the metal while epoxy coating decreased corrosion. TMA and epoxy coated nickel-titanium wires had the least corrosive potential. The breakdown potential of TMA wire could not be reached. TMA remained passive throughout the entire range of $2000 \mathrm{mV}$. The breakdown potential for nickel-titanium and stainless steel ranged from 300-750 mV. Upon microscopic examination, Kim and Johnson found extensive pitting and localized corrosion on stainless steel, nickel-titanium, and nitride coated wires subjected to potentiostatic anodic polarization. All three types of wire showed significant changes in surface morphology following anodic dissolution. Using SEM photographs, epoxy coated nickel-titanium wires and TMA wires showed no detectable difference in surface morphology between wires exposed to potentiostatic anodic polarization and those that were not. 
Potentiostatic anodic polarization technique is a commonly accepted method of performing corrosion testing. Several basic concepts must be understood and applied when performing this testing procedure. These concepts include corrosion, passivity, oxidation, kinetics and the oral environment. A metal can be described as being either active or passive with relation to its environment depending on the observed rate of corrosion. The use of potentiostatic anodic polarization will enable one to quantify active and passive systems and determine when a system changes from a passive to an active state. The transition correlates with the onset of the corrosive process of the metal. $^{31}$ Natural corrosion can be accurately duplicated using potentiostatic anodic polarization if the normal environment of the metal can be reproduced. The natural conditions should be duplicated as closely as possible when using this process. The physical state of the metal, and the solution environment, including aerated conditions are important factors. ${ }^{30,32}$

The American Society for Testing and Materials (ASTM) has a standard reference test for potentiostatic anodic polarization measurements. There are several elements required for making the measurements. These include an electrochemical corrosion sell, a data acquisition device, and a potentiostat. The corrosion cell is made up of a polarization cell and a reference cell connected by a salt bridge. The polarization cell contains the working electrode, the auxilliary or counter electrode, and a Luggin capillary probe for the salt bridge connection. The working electrode is the test specimen and the auxiliary electrode can be platinum or graphite. The reference cell holds the reference electrode, such as a saturated calomel electrode, 
and the tubing connection of the salt bridge. Wires connect the corrosion cell and the potentiostat.

The potentiostat is used for performing tests utilizing potentiostatic anodic polarization. The potential of a test sample is maintained at a desired level by the potentiostat. It monitors the potential between the working electrode and a reference electrode, and automatically alters the current between the working electrode and a counter electrode to maintain the desired potential. 


\section{CHAPTER III}

\section{METHODS AND MATERIALS}

\section{SAMPLE DESCRIPTION}

The wire samples were obtained from three manufacturers ("A" Co., San Diego, California; Ormco Co., Glendora, California; and 3M Unitek, Monrovia, California). Round wires with a diameter of 0.016 inches were utilized. At least two samples of each type were tested (a third was tested if required) making a total of 24 samples that were tested for this study. Two different bracket types were utilized: Orthos stainless steel and Transcend

ceramic (Ormco Co., Glendora, California). The Transcend caramic bracket has no metal slot.

A. Archwires used in this study

1. $0.016 ”$ stainless steel (“A” Co.)

2. $0.016 " \mathrm{NiTi}$ (Ormco)

3. 0.016" titanium-molybdenum alloy (Ormco)

4. $0.016 " 24 \mathrm{k}$ gold plated stainless steel (Unitek)

B. Bracket used in this study

1. Ormco Orthos stainless steel $0.022 "$ slot: mandibular central incisor

2. Ormco Ceramic bracket 0.022 " slot: mandibular central incisor 
The metal compositions of the samples are reported in Table 1 below.

\begin{tabular}{|c|c|c|c|c|c|c|c|}
\hline & Ni & Cr & Fe & Ti & Sn & Zr & Mo \\
\hline S.S. (“A” Co.) & $9 \%$ & $18 \%$ & $73 \%$ & & & & \\
\hline NiTi (Ormco) & $55 \%$ & & & $45 \%$ & & & \\
\hline TMA (Ormco) & & & & $78 \%$ & $4 \%$ & $6 \%$ & $11.5 \%$ \\
\hline $\begin{array}{c}\text { S.S. Bracket } \\
\text { (Ormco) }\end{array}$ & $14 \%$ & $18 \%$ & $65 \%$ & & & & $3 \%$ \\
\hline
\end{tabular}

Table 1. Percentage by weight of element composition in test samples, (from manufacturers Material Safety Data Sheets).

C. Surface exposure of the alloys

1. A $30 \mathrm{~mm}$ length of archwire was exposed to anodic polarization with a calculated surface area of $0.38 \mathrm{~cm}^{2}$.

2. The bracket face minus adhesive portion of the base was exposed to anodic dissolution. The posterior bracket base surface was protected with resin (acrylic fingernail polish). The calculated surface area was $.35 \mathrm{~cm}^{2}$. This was calculated manually by measuring individual parts of the bracket using electronic calipers to arrive at a sum surface area.

D. Preparation of the samples

1. The wire samples were measured from one end and marked so that 30 $\mathrm{mm}$ of the wire could then be placed in the solution accurately. All 
samples were tested in the condition that they arrived from the manufacturer to simulate actual clinical use.

2. The bracket samples had to be attached to the end of a 0.30 " stainless steel wire so that the current could be delivered to the sample when placed into the testing solution. This was accomplished by using a conducting metal paint (Ladd Industries, Burlington, Vermont) to join the adhesive base of the bracket to the carrier wire. After the two parts were bonded together, the back of the bracket and the length of wire were covered with resin (acrylic fingernail polish) to isolate the bracket face for the corrosion study.

3. The combined samples of brackets and wires were prepared by first cutting a $30 \mathrm{~mm}$ length of wire and ligating it into the bracket slot by the use of an elastomeric tie (Ormco "O" tie). The bracket was then attached to the end of a stainless steel wire so that the current could be delivered to the area of interest when placed into the testing solution. This was accomplished the same way as the bracket samples in \#2. To verify the methodology, an additional bracket/wire assembly was tested. The bracket was ligated to one of the stainless steel archwires by using an elastomeric tie and the mesh backing was covered with acrylic. Both the bracket and $30 \mathrm{~mm}$ of the archwire were submerged into the solution. The electrode was attached to the stainless steel wire as in \#1. 


\section{RESEARCH DESIGN}

Potentiostatic anodic polarization curves for wires, brackets and wire-bracket combinations were recorded using an electrochemical corrosion cell (Bank Elektroniks, Clausthal, Germany) with $0.9 \% \mathrm{NaCl}$ solution (Baxter Healthcare Corp., Deerfield, Illinois). Photographs of the surface morphology using standard photography were made.

Each sample was tested as it arrived from the manufacturer to simulate normal use in a clinical orthodontic setting. The sample was then placed into the working electrode fixture and adjusted so that it was submerged in $900 \mathrm{ml}$ of saline solution in the polarization cell. The tip of the Haber-Luggin probe was positioned approximately $2 \mathrm{~mm}$ from the working electrode. All electrodes were then connected to the potentiostat at this point. Equilibration was then allowed for 60 minutes at room temperature. This allowed for the determination of a resting potential. At 60 minutes, potential and current density measurements were started and readings taken at intervals of one minute. At 65 minutes the potential was increased to $50 \mathrm{mV}$ and subsequent steps will be $50 \mathrm{mV}$ every 5 minutes. This process was continued until the breakdown potential for the sample, or until the $2000 \mathrm{mV}$ potentiostat maximum was reached.

To verify testing accuracy as recommended by the American Society for Testing and Materials (ASTM), at least two samples each were tested. If one of a particular sample varied significantly, then a third sample was tested. Potentiostatic anodic polarization curves were constructed for each. The breakdown potential for each bracket/wire individual and coupled sample types was then determined from the 
polarization curves. This point was determined manually from the graphs by the ascending slope of the polarization curve and finding the corresponding millivolt value. The samples were then evaluated and photographed. To evaluate any confounding effects of crevice conditions, a stainless steel wire was tested when coupled with a ceramic bracket. Photographs of the alloys' surfaces were then taken using standard black and white photography to demonstrate the surface characteristics following potentiostatic anodic polarization.

A 24k gold-coated stainless steel wire from 3M Unitek was also tested. Additionally, the gold wire was scratched by using a slow speed handpiece with a heatless stone. This removed $2 \mathrm{~mm}$ of the gold wire coating, exposing the underlying stainless steel. The scratched wire was tested using anodic polarization.

\section{EQUIPMENT}

The equipment needed for this research investigation was:

A. Wenking MP 95 potentiostat for anodic polarization (Bank Elektronik, Clausthal, Germany) (Figure 1).

B. Computer, screw board terminal (STP 37, Keithley Instruments, Tauton, Massachusetts), data acquisition board (DAS 1602, Keithley Instruments), and data acquisition program (CPC-RP potentiostat software, Bank Elektronik).

C. Zelledn electrochemical corrosion cell (Bank Elektronik) (Figure 2).

1. The polarization cell consists of a $1000 \mathrm{ml}$ flask with a teflon lid. The lid has six holes, three of which will be closed with neoprene stoppers. 
The remaining three holes hold glass fixtures that receive the working electrode (wire and bracket sample) fixture, the auxiliary or counter electrode (platinum foil), and a Haber-luggin probe. The working electrode fixture is constructed of glass tubing and teflon drilled with a small hole enabling wire samples to be held in place.

2. Reference cell with reference electrode (saturated calomel electrode, B3410, Schott Gerate, Hoffheim, Germany). The reference cell is connected to the polarization cell by way of an electrolyte $(0.9 \% \mathrm{NaCl})$. 


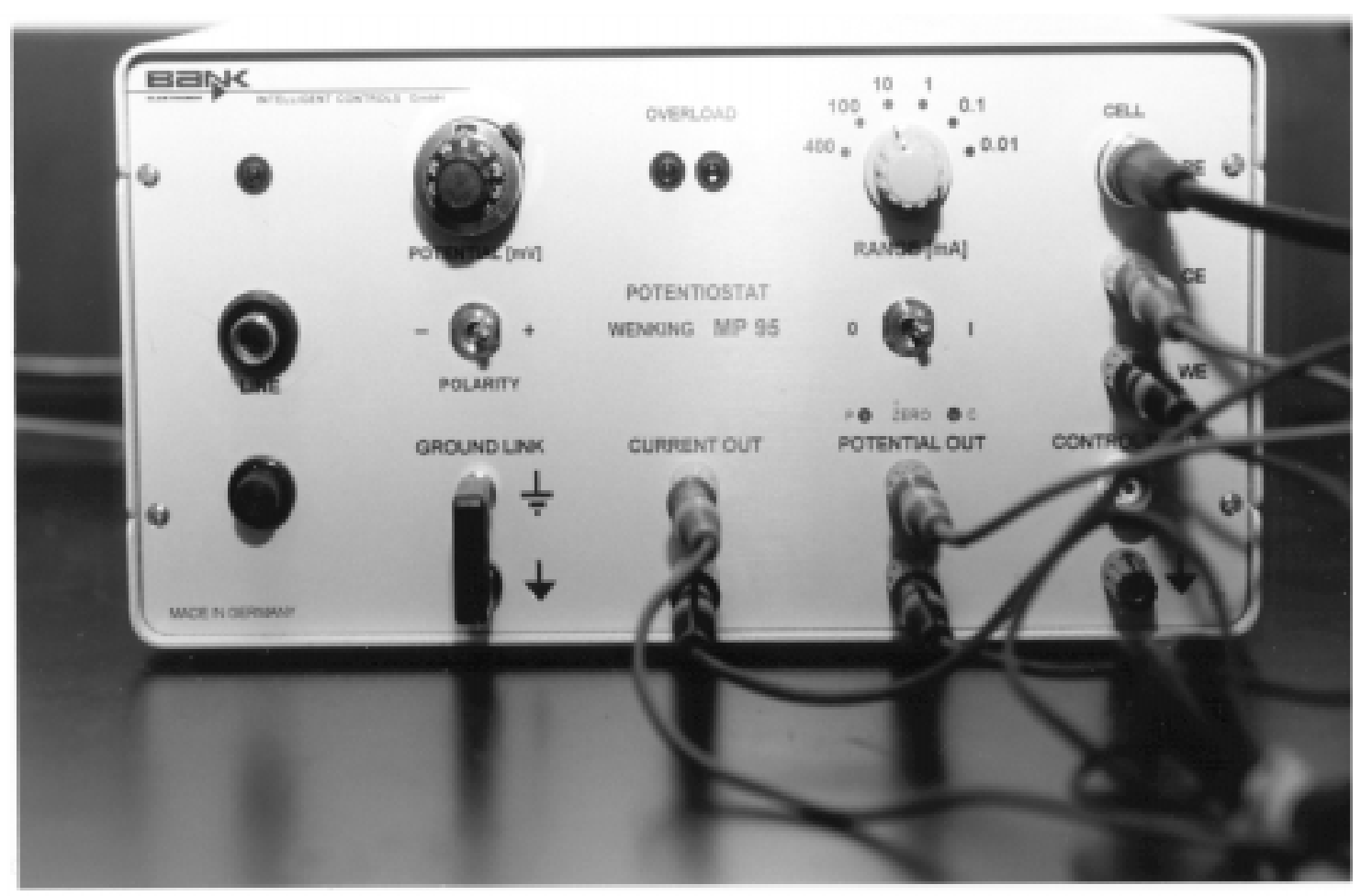

Figure 1. Potentiostat 


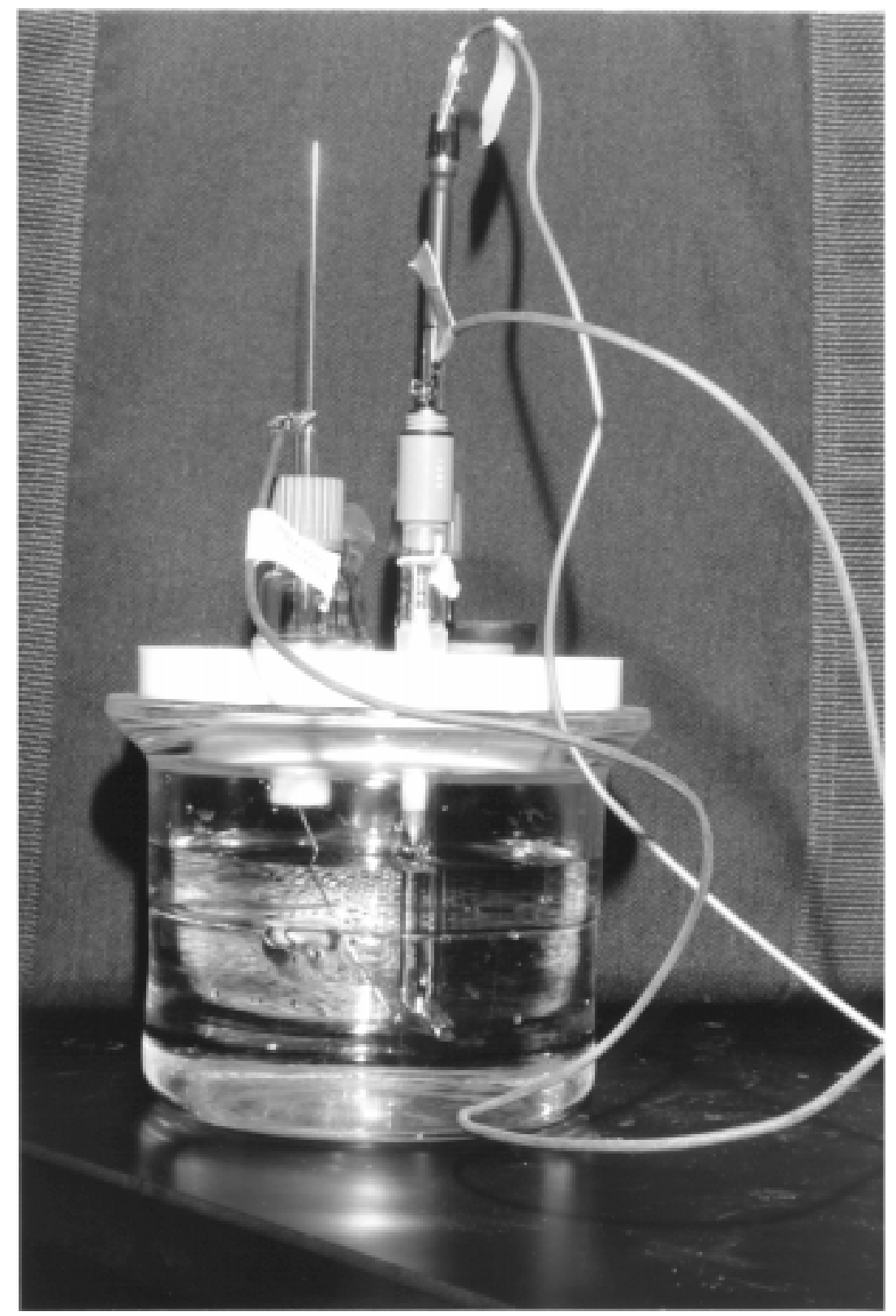

Figure 2. Polarization cell 


\section{STATISTICAL TREATMENT}

The mean and standard deviation for breakdown potential and maximum current density were computed. Potentiostatic anodic polarization curves were constructed for each wire, bracket, and bracket/wire combination. Data was compared using ANOVA and Tukey-Kramer least significant difference tests. 


\section{CHAPTER IV}

\section{RESULTS AND DISCUSSION}

\section{RESULTS}

After completion of the experiments, potentiostatic anodic polarization curves were constructed and breakdown potentials were determined for each of the samples (Figures 5-14). The breakdown potentials of the individual samples are seen in Table 2.

\begin{tabular}{|l|l|l|l|}
\hline Stainless Steel Bracket & $200 \mathrm{mv}$ & $200 \mathrm{mv}$ & $200 \mathrm{mv}$ \\
\hline Stainless Steel wire & & & \\
\hline NiTi & $600 \mathrm{mv}$ & $600 \mathrm{mv}$ & $800 \mathrm{mv}$ \\
& $1600 \mathrm{mv}$ & $1600 \mathrm{mv}$ & $1600 \mathrm{mv}$ \\
\hline TMA & & & \\
& $>2000 \mathrm{mv}$ & $>2000 \mathrm{mv}$ & $>2000 \mathrm{mv}$ \\
& & & \\
\hline
\end{tabular}

Table 2. Breakdown potentials of individual samples. 
The ANOVA showed the difference in breakdown potential was statistically significant $(\mathrm{p}<0.001)$. The Tukey-Kramer test showed each product in table 2 to be statistically different from all other products $(\mathrm{p}<0.05)$.

The results indicate that corrosion occurred more readily in stainless steel brackets and somewhat slower in stainless steel wires. The value of $800 \mathrm{mv}$ obtained for the stainless steel wire was out of line with the other values for unknown reasons, but was not disregarded. The NiTi wires were much more corrosion resistant, but ultimately broke down. The breakdown potential of the TMA wire could not be reached throughout the $2000 \mathrm{mv}$ range of testing.

Visual inspection of the tested samples of stainless steel brackets, stainless steel wires and NiTi wires revealed extensive pitting and changes in surface morphology (Figures 3,4). The most notably corroded were the stainless steel brackets which not only corroded earlier but also more extensively. This was seen throughout the bracket face, on the base and the tie wings. Changes in color were noted and even fracturing of the stainless steel wire occurred when taken throughout the entire 2000 mv testing range. NiTi wires exhibited a color change from silver to dark gray after being subjected to potentiostatic anodic polarization. TMA did not exhibit any notable changes in surface morphology or structural integrity. Note the discoloration and pitting on the stainless steel brackets in Figures 3 and 4. 


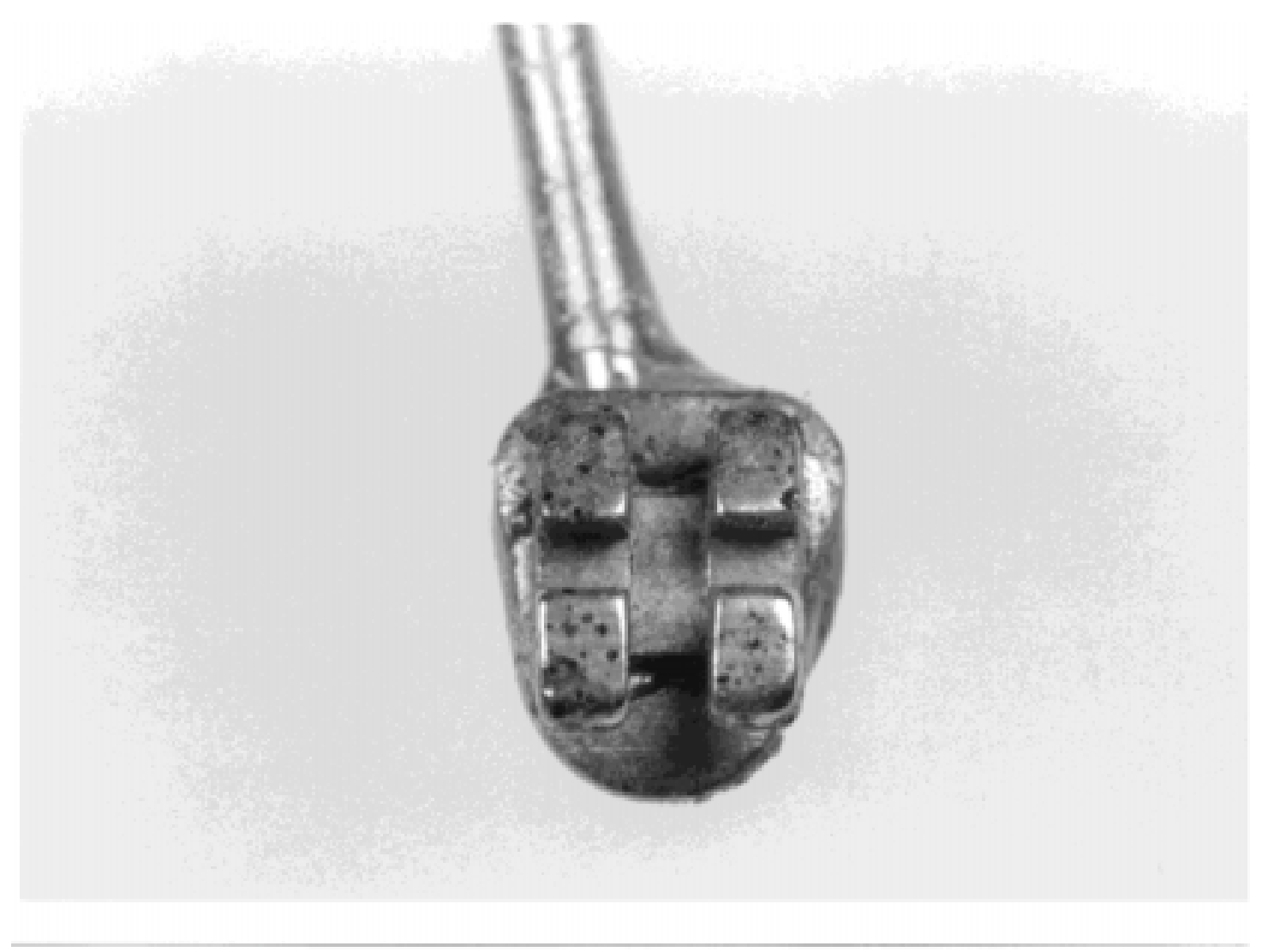

Figure 3. Stainless steel bracket after testing 


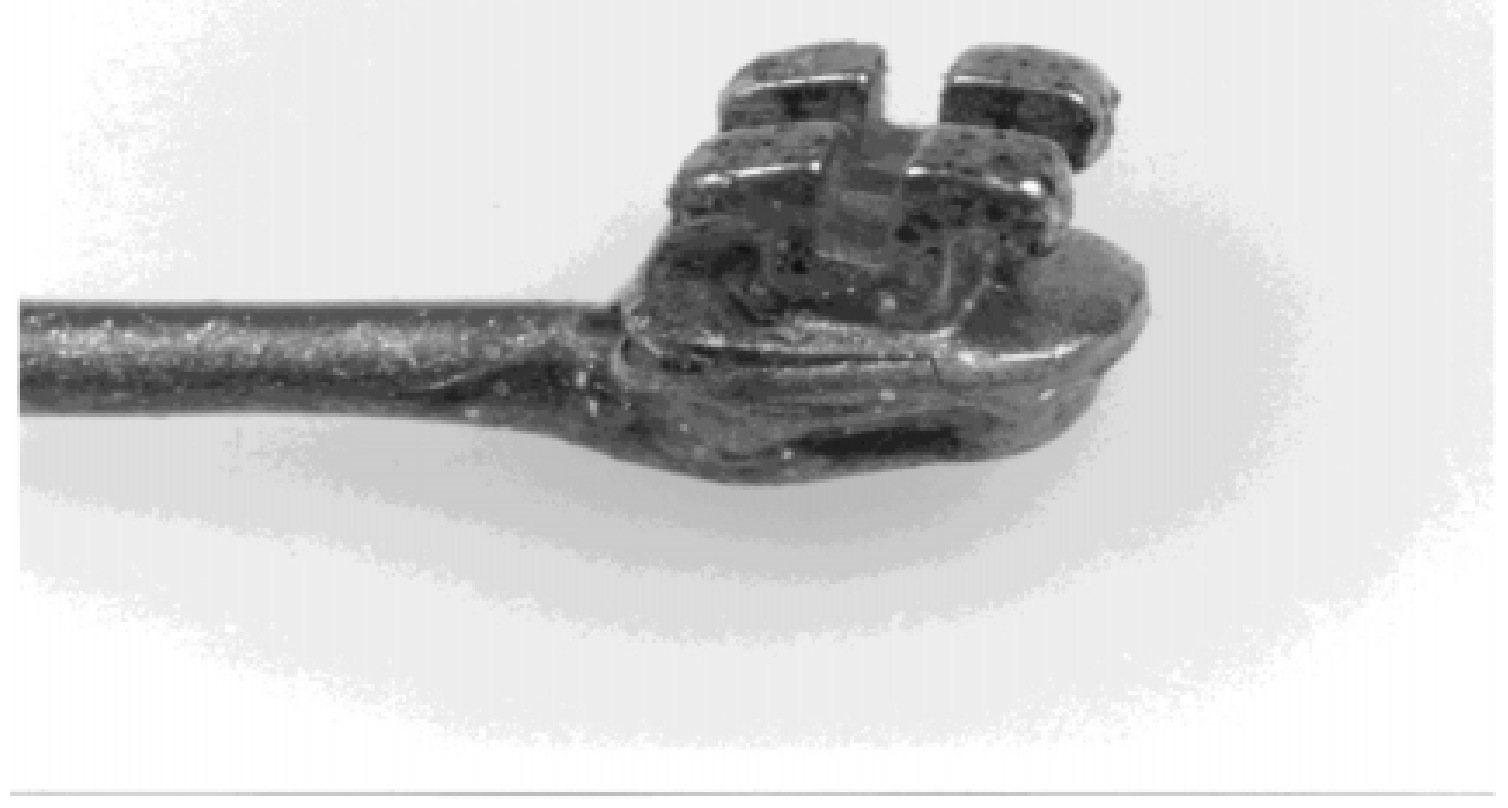

Figure 4. Stainless steel bracket after testing

The breakdown potentials for the wires when combined with a stainless steel bracket are seen in Table 3.

\begin{tabular}{|l|l|l|l|}
\hline Stainless steel & $200 \mathrm{mv}$ & $200 \mathrm{mv}$ & \\
\hline NiTi & $200 \mathrm{mv}$ & $200 \mathrm{mv}$ & \\
& & & \\
\hline TMA & $200 \mathrm{mv}$ & $200 \mathrm{mv}$ & $200 \mathrm{mv}$ \\
& & & \\
\hline
\end{tabular}

Table 3. Breakdown potentials of coupled samples 
When galvanically coupling these wires with a stainless steel bracket and subjecting them to potentiostatic anodic polarization, the results were quite surprising. The corrosive potential of the stainless steel bracket seemed to determine the level at which the coupled samples would begin to breakdown. The breakdown potential was independent of the type of wire that was engaged in the bracket slot and all samples broke down near the potential that the stainless steel bracket broke down when tested alone. This occurred whether the wire/bracket couple was attached to the potentiostat via the wire in the slot or a coated wire glued to the back of the bracket.

After reaching their breakdown potential, all bracket-wire couples exhibited surface changes associated with corrosion. Color changes and pitting occurred in all of the samples with the exception being the TMA wire (and gold-coated wire). While the TMA wire did not show any visible signs of corrosion, the stainless steel bracket of the couple did exhibit these effects.

To investigate any possible crevice corrosion effects on the wires when coupled with a bracket an additional test was conducted. A $30 \mathrm{~mm}$ stainless steel wire sample was engaged in the slot of a ceramic bracket and tested using potentiostatic anodic polarization. The breakdown potential was found to be $550 \mathrm{mv}$. The corrosive potential was nearly the same as the potential of the stainless steel wire when tested alone.

The gold-coated wire did not breakdown throughout the $2000 \mathrm{mv}$ testing range. The scratched gold-coated wire had a breakdown potential of $500 \mathrm{mv}$. This level was very close to the value found $(600 \mathrm{mv})$ when testing a stainless steel wire alone. The slight variation in values could be due to different stainless steel of the two samples or 
lack of a complete passivation layer on the wire. It should be noted that the gold coating was difficult to disrupt and the use of a handpiece was required to alter the breakdown potential of the gold wire sample.

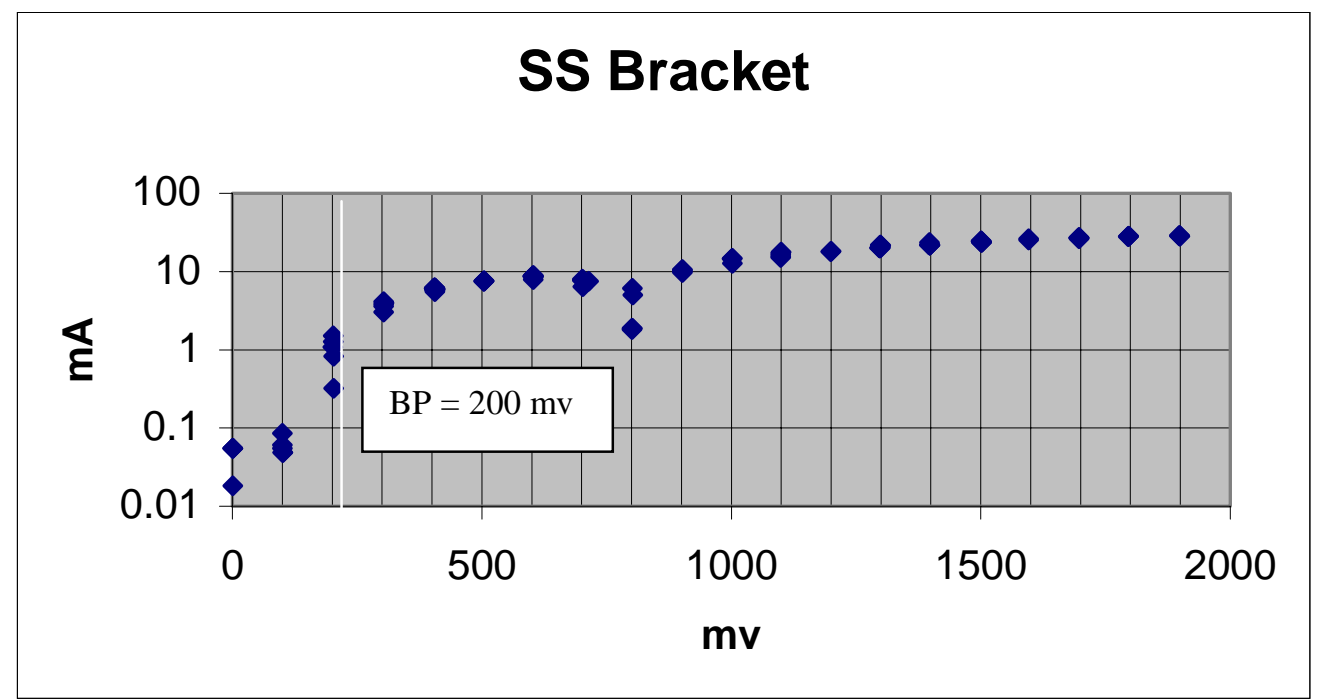

Figure 5. Potentiostatic anodic polarization curve for stainless steel bracket. Breakdown potential was found to be $200 \mathrm{mv}$. 


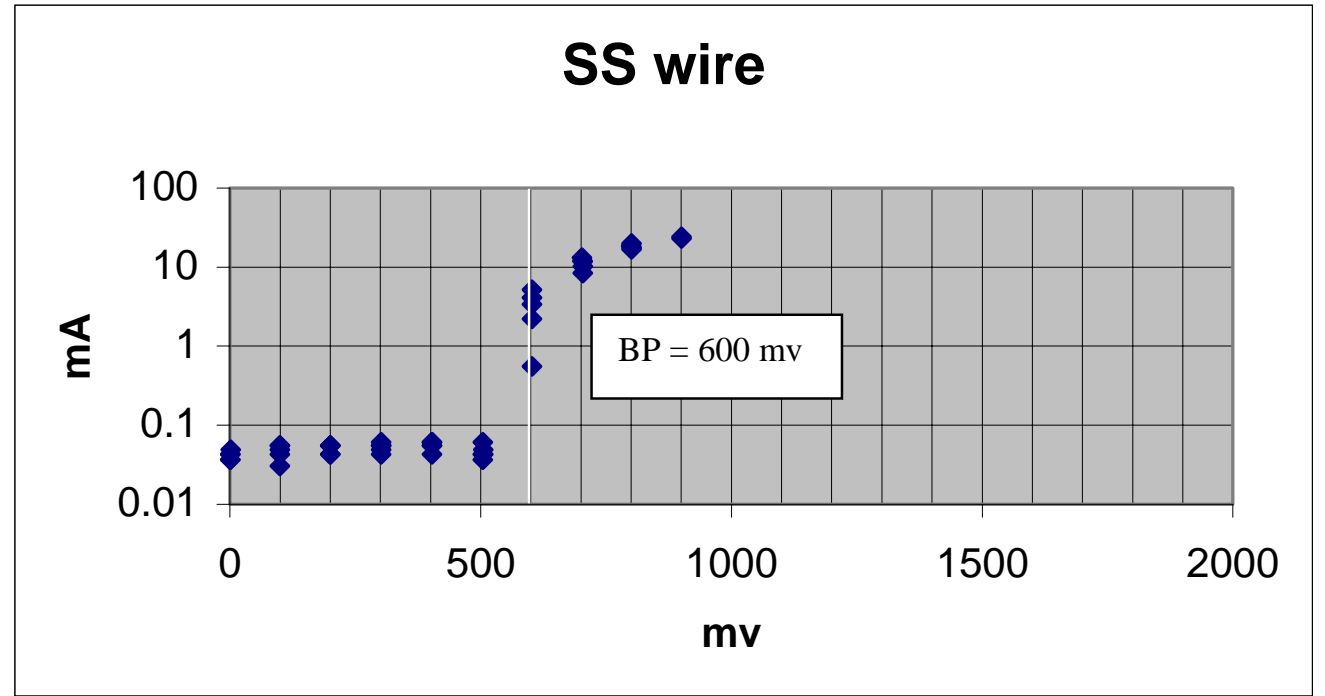

Figure 6. Potentiostatic anodic polarization curve for stainless steel wire.

Breakdown potential was found to be $600 \mathrm{mv}$.

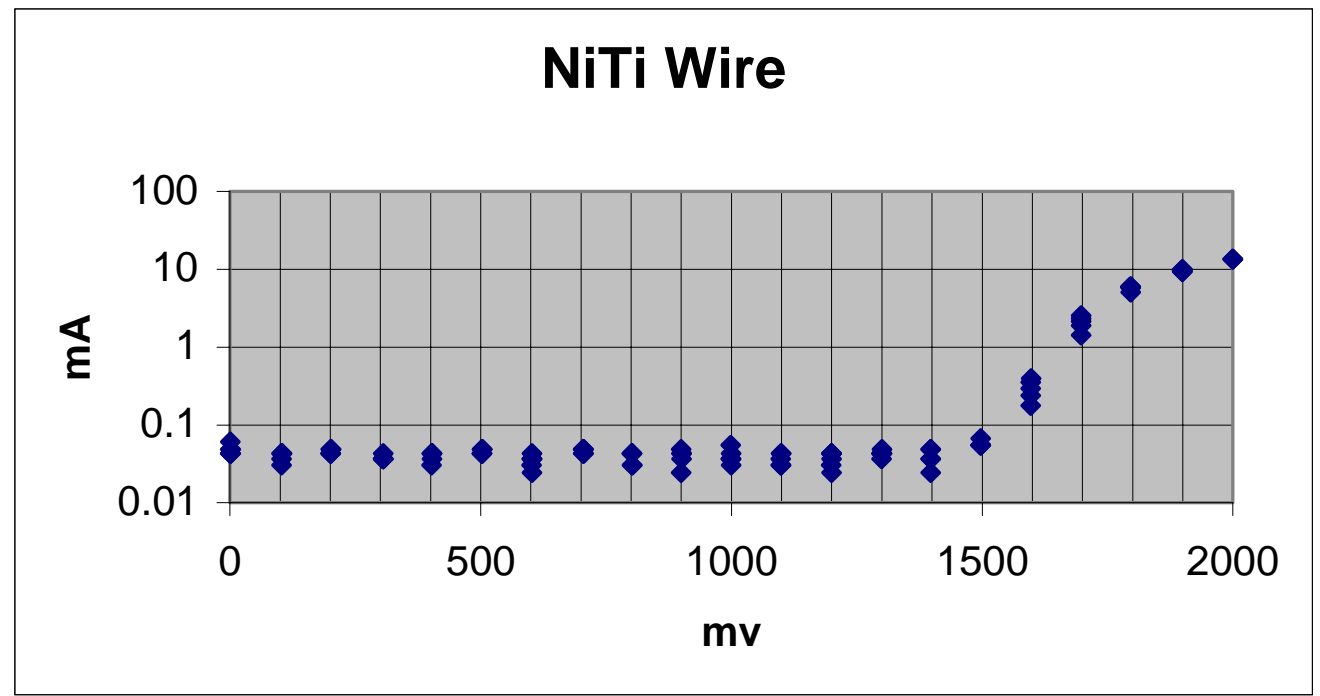

Figure 7. Potentiostatic anodic polarization curve for NiTi wire. Breakdown potential was found to be $1600 \mathrm{mv}$. 


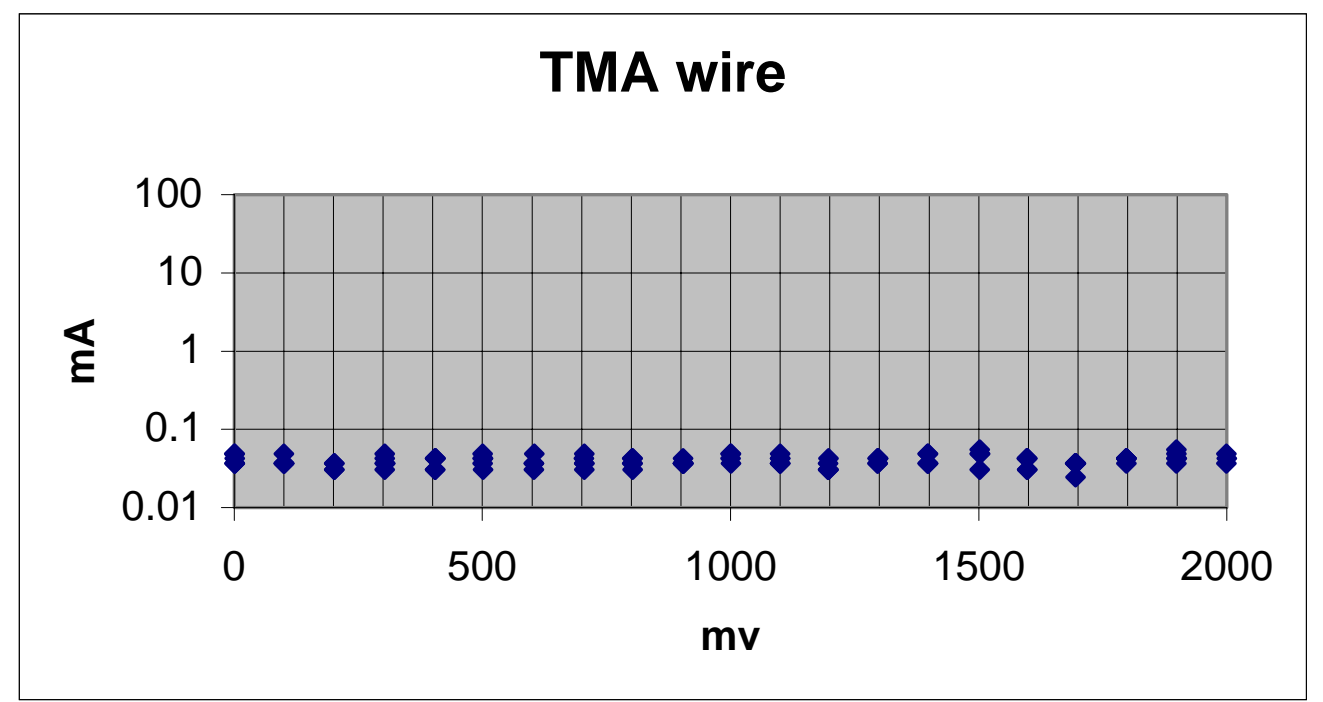

Figure 8. Potentiostatic anodic polarization curve for TMA wire. Breakdown potential was found to be $>\mathbf{2 0 0 0 m v}$.

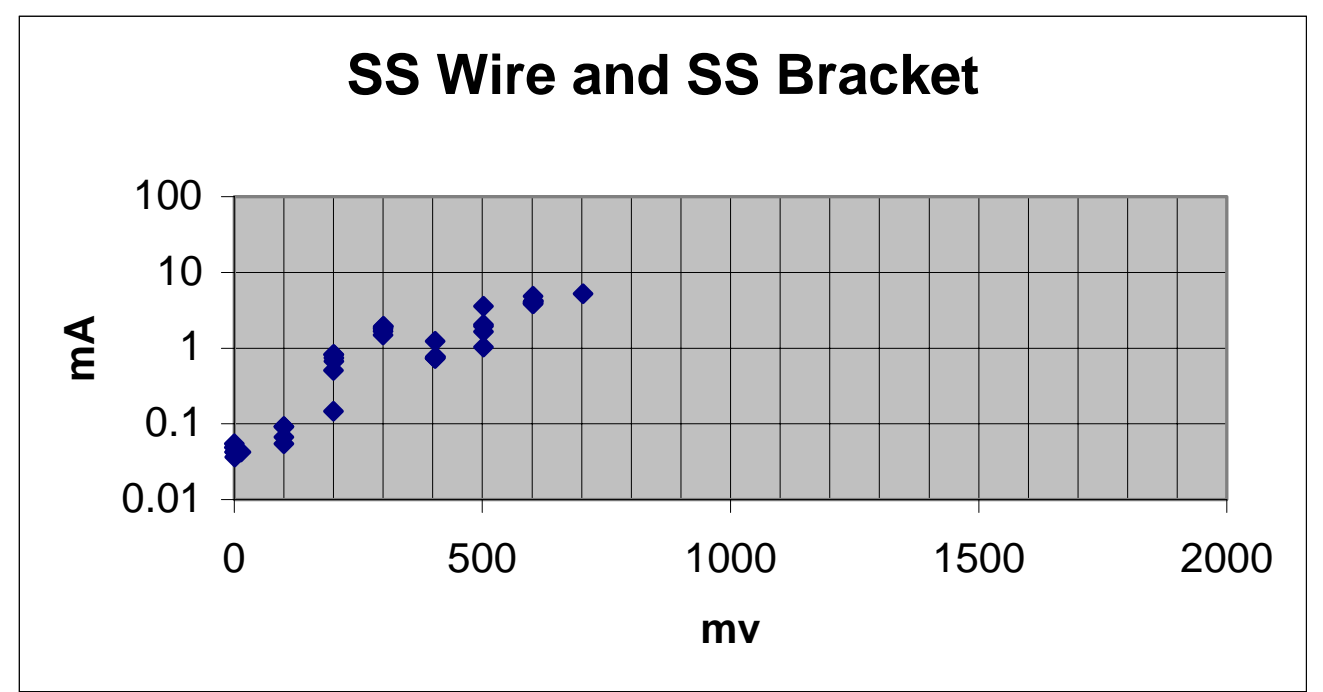

Figure 9. Potentiostatic anodic polarization curve for stainless steel wire and stainless steel bracket combination. Breakdown potential was found to be $200 \mathrm{mv}$. 


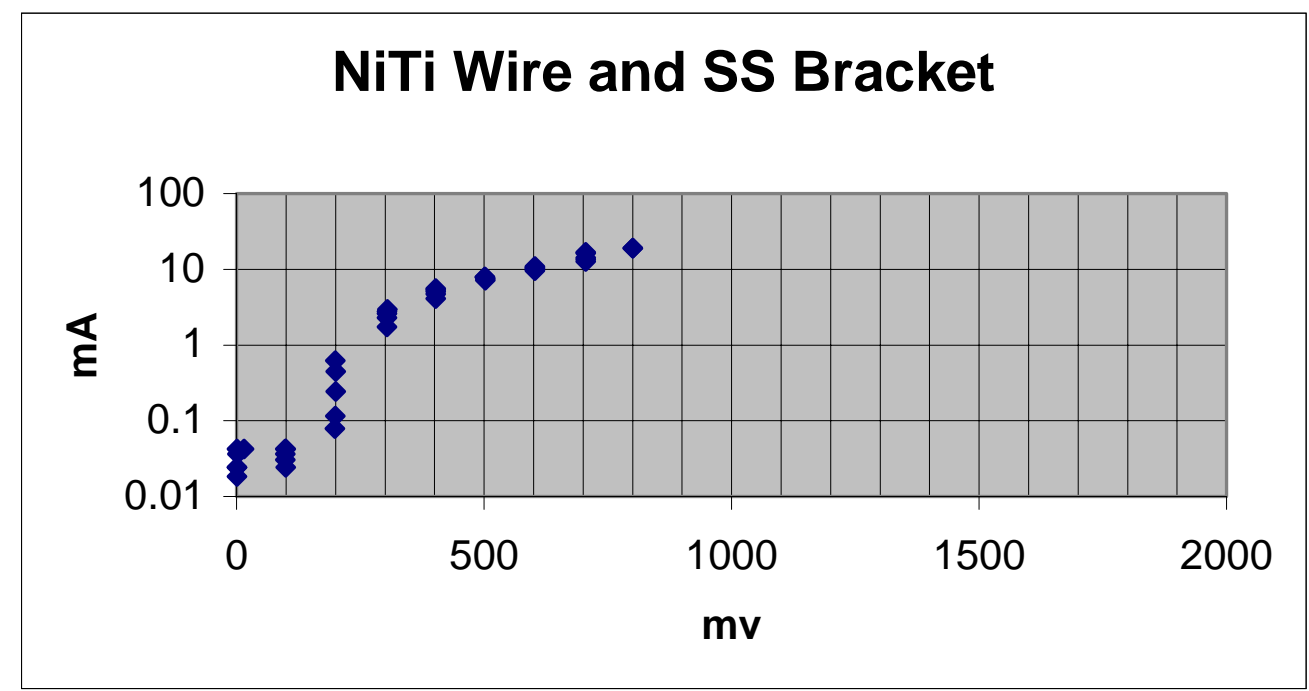

Figure 10. Potentiostatic anodic polarization curve for NiTi wire and stainless steel bracket combination. Breakdown potential was found to be $200 \mathrm{mv}$.

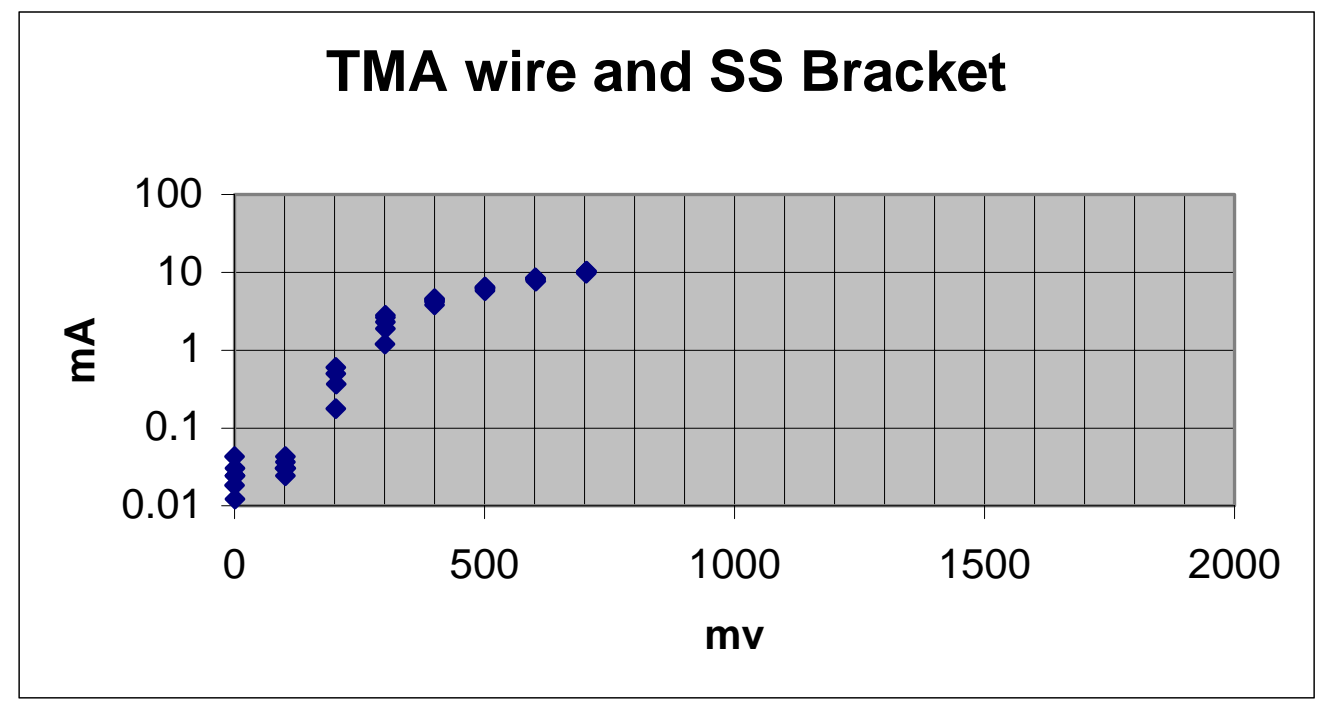

Figure 11. Potentiostatic anodic polarization curve for TMA wire and stainless steel bracket combination. Breakdown potential was found to be $200 \mathrm{mv}$. 


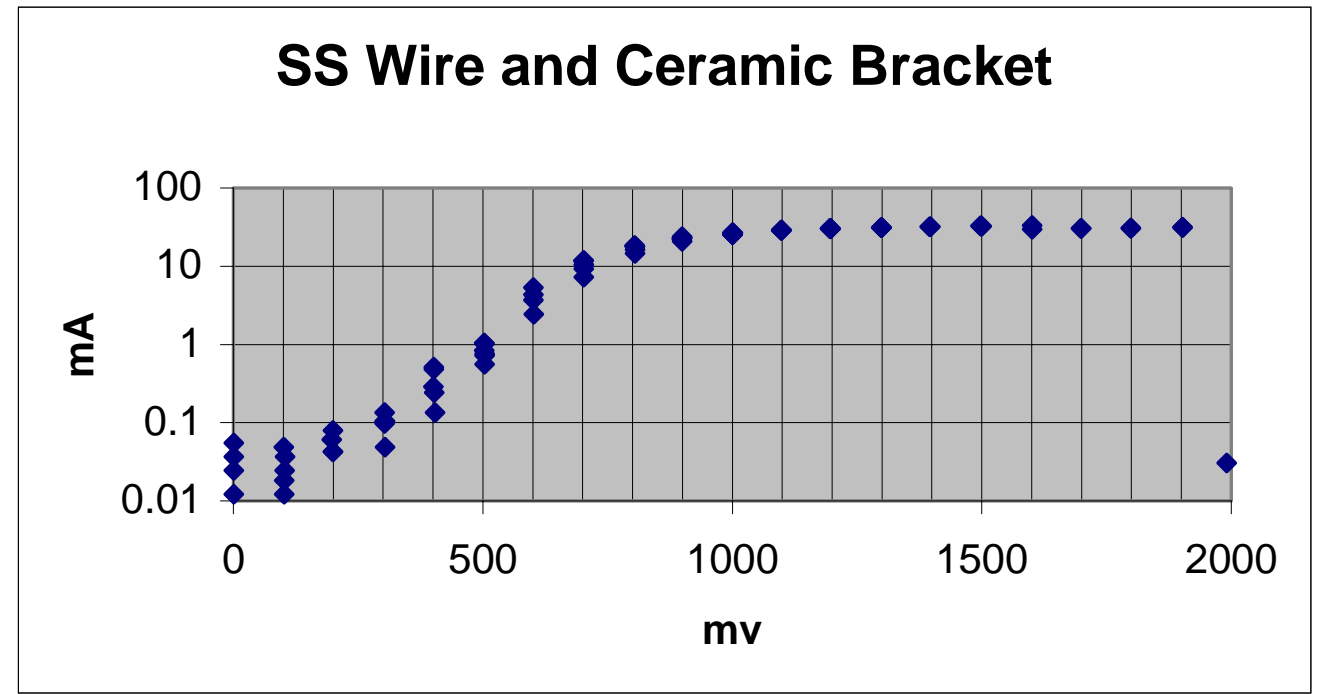

Figure 12. Potentiostatic anodic polarization curve for stainless steel wire and ceramic bracket combination. Breakdown potential was found to be $550 \mathrm{mv}$.

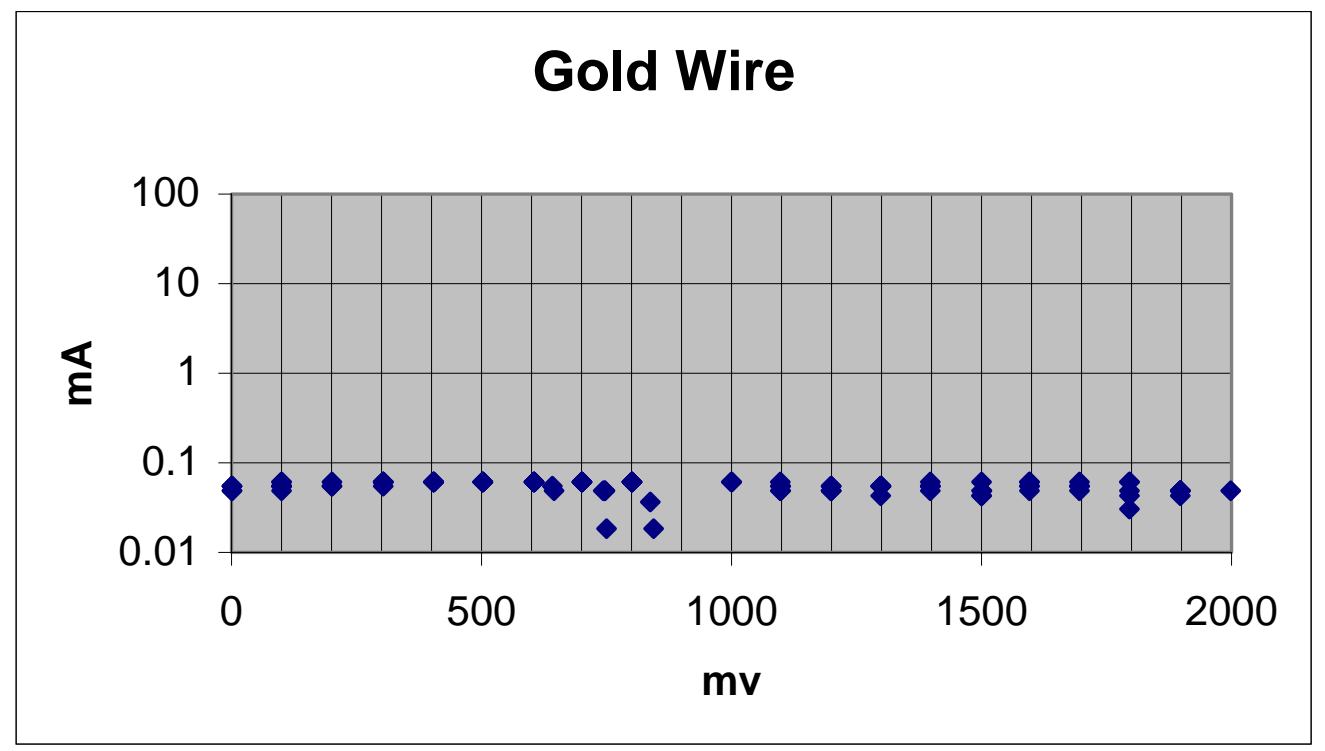

Figure 13. Potentiostatic anodic polarization curve for gold-coated stainless steel wire. Breakdown potential was found to be $>2000 \mathrm{mv}$. 


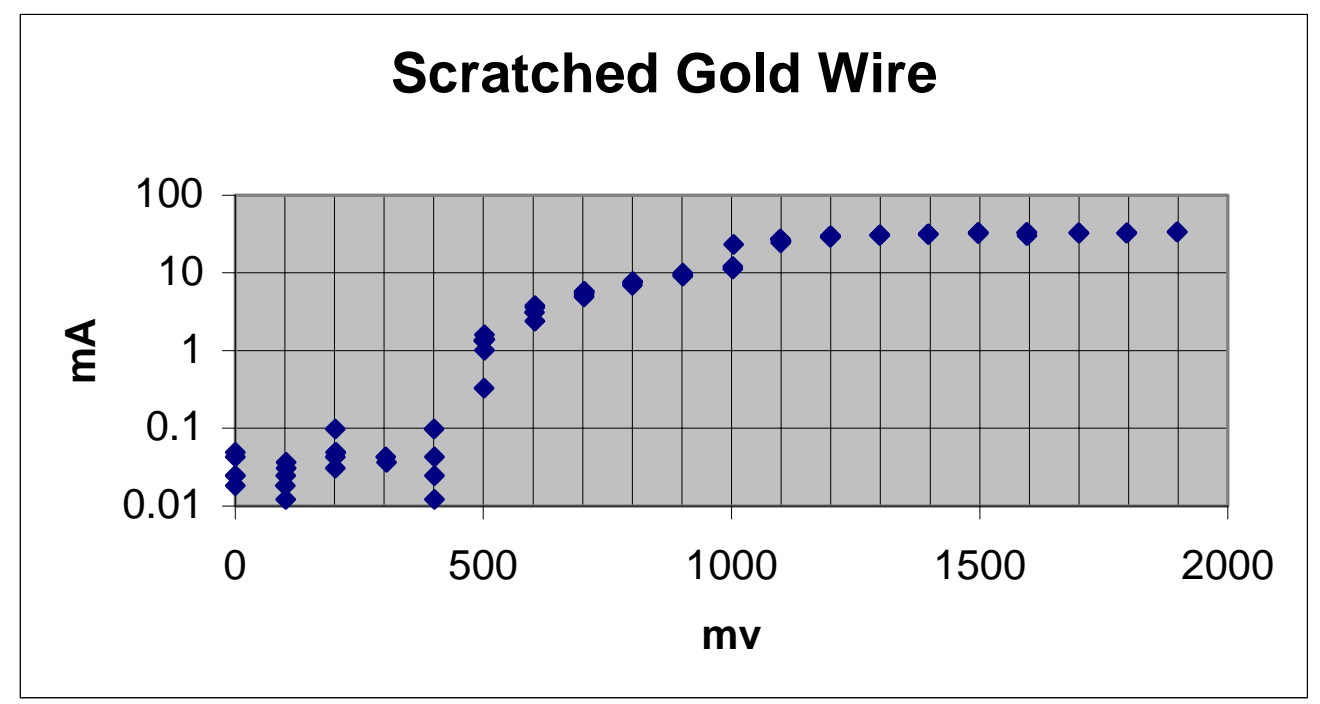

Figure 14. Potentiostatic anodic polarization curve for "scratched" gold-coated stainless steel wire. Breakdown potential was found to be $500 \mathrm{mv}$.

\section{DISCUSSION}

The breakdown potential was determined for all of the samples tested by using potentiostatic anodic polarization. The breakdown potentials indicate the point at which the oxide film of the metal is interrupted and the dissolution of the metal begins. The lower the value of the breakdown potential, the higher the susceptibility to corrosion. Among the wires, the greatest susceptibility to corrosion was seen in stainless steel followed by nickel-titanium. The breakdown potential of gold coated and TMA wires could not be reached. As noted earlier, the most susceptible was the stainless steel bracket, which recorded a value of $200 \mathrm{mv}$.

When coupling the wires and the stainless steel bracket, the outcomes were all essentially the same. All of the three wire types tested with the stainless steel bracket 
recorded breakdown potentials of $200 \mathrm{mv}$. The samples all corroded at the level where the stainless steel bracket was found to corrode when tested alone. The bracket determined the corrosive potentials of the combination samples regardless of the wire that was placed in the slot.

To confirm this finding, a stainless steel wire was tested with a ceramic bracket. The ceramic bracket was considered to be a control in that it contains no metal and has no corrosion potential. The results indicated that the breakdown potential of the sample was approximately the same as the value that the stainless steel wire would have yielded if tested alone. The breakdown potential for the sample was found to be $550 \mathrm{mv}$. This supported the theory that the stainless steel bracket was the weak link in the corrosion potentials of the combined samples.

Additionally, a 24k-coated stainless steel wire from 3M Unitek was tested. The gold wire remained inert throughout the entire $2000 \mathrm{mv}$ range. The experiment was unable to reach its breakdown potential. The gold wire was then scratched to remove the outer protective gold layer. The sample was then tested using potentiostatic anodic polarization. The breakdown potential was then found to be $500 \mathrm{mv}$. This value corresponds to the value found for the other stainless steel wire samples. This finding shows that the protective gold layer is only effective against corrosion when intact. However it should be pointed out that the gold coating was not easy to remove. Throughout orthodontic treatment, the appliances are subjected to a dynamic environment that could possibly abrade the surface of the wire and change the corrosive potential. In addition, clinically bending or cutting the archwire could alter 
the corrosive properties of the wire and the appliance system. Additionally, the reuse or recycling of appliances could affect the corrosion resistance of the system.

Different manufacturers could have different corrosive potentials for their wires or brackets. Various compositions of the metals could change the breakdown potential. Also, the manufacturing process could have a significant effect. The surface smoothness or finish of the metals would play a role in the corrosive potentials of the wires or brackets. Finally, the shape of a particular bracket design could affect the crevice conditions, which may alter the corrosive potential.

The two wires tested that had the greatest corrosive resistance were the TMA and gold-coated wires. Both titanium and gold are noble metals with very high corrosive resistance and these wires demonstrated such when subjected to potentiostatic anodic polarization. TMA is very unlikely to release ions intraorally and also contains no nickel (stainless steel contains $9 \%$ and NiTi contains $55 \%$ nickel by weight). Because of its flexibility and elastic properties, it would be a good substitute for NiTi in nickel sensitive patients. Twenty-four carat gold-coated wires are now being used for cosmetic purposes and may be found useful in patients with nickel allergies. The resistance of the gold allows for little ion release intraorally. However, if the protective gold coating were removed or abraded then the underlying metal would be subject to the intraoral elements and corrosion and ion release could occur. These wires are used in conjunction with gold-coated brackets. These bracket types were not tested for corrosion resistance, but they may be more resistant than a standard stainless steel appliance system. The gold-coating would also be susceptible to scratching in the same manner as the gold-coated wires. In theory, their resistance to 
corrosion would then be reduced as a result of exposure of the underlying metal.

There may be a tendency for the clinician to use and re-use the gold-coated wires and brackets due to their increased expense. The additional time spent intraorally could lead to an increase in the amount of wear and corrosion of the alloys. This has not been investigated at this point.

Stainless steel brackets were found to be the most susceptible to breakdown when subjected to potentiostatic anodic polarization. The brackets had a breakdown point of $200 \mathrm{mv}$ and showed significant surface corrosion. In addition, the brackets contain nickel and make up a significant amount of surface area of the orthodontic appliance system. The brackets are used throughout the mouth and are in almost constant contact with the oral mucosa. The nickel sensitive patient would be well served to avoid the use of a stainless steel bracket system. The leaching of nickel ions may cause contact dermatitis or other allergic conditions. In addition, the shape of the brackets and the nature of the wire/slot relationship allows for crevice corrosion. Metals that contain crevices encourage the corrosion process to intiate and propogate. A smooth surface is much more corrosion resistant than an irregular or rough surface. Also, intraorally areas of the brackets that are difficult to clean which may lead to localized areas of lowered $\mathrm{pH}$. The lower the $\mathrm{pH}$ levels, the greater the likelihood of metal corrosion.

The dynamic environments to which orthodontic alloys are subject, makes the onset of corrosion somewhat variable from case to case. The possibility of wear from mastication and type of diet may disrupt the passive layer. Oral hygiene may play a 
significant role in the corrosion of the appliances. Scratches and surface irregularities may also have a significant effect.

The samples in this study were subjected to physiologic saline $(0.9 \% \mathrm{NaCl})$ instead of true saliva. The tests were conducted at room temperature, which was very close to the standard $37^{\circ} \mathrm{C}$ found intraorally. The experiment was also conducted without purging oxygen into the solution. It should be noted that small changes in $\mathrm{pH}$ and temperature were kept to a minimum and should have a very limited effect on the sample outcome. Surface finishes and manufacturing processes could have a more profound effect on the alloys when subjected to potentiostatic anodic polarization. Addressing the hypothesis directly: there was a significant difference in the corrosive potential of stainless, NiTi, and TMA orthodontic archwires when tested using potentiostatic anodic polarization testing. There was not a significant difference in the corrosive potential of stainless steel, NiTi, and TMA orthodontic archwires when galvanically coupled with a stainless steel bracket. There was a significant difference in the corrosive potential of stainless steel, NiTi, and TMA orthodontic archwires when galvanically coupled with a stainless bracket versus the corrosive potential of the wire alone using potentiostatic anodic polarization testing. 


\section{CHAPTER V}

\section{SUMMARY AND CONCLUSIONS}

The purpose of this study was to compare the corrosive potential of stainless steel, nickel titanium, and TMA orthodontic wires when tested alone versus when paired with a stainless steel bracket. At least two samples of each wire and bracket/wire combination were tested. Each sample was subjected to potentiostatic anodic polarization in $0.9 \% \mathrm{NaCl}$ solution at room temperature with a neutral $\mathrm{pH}$. Using a Wenking MP 95 potentiostat, the breakdown potential of each sample was determined. The potentiostat was connected to an electrochemical corrosion cell. A data acquisition program was used to record data needed for the construction of potentiostatic anodic polarization curves. Photographs were taken of the samples to demonstrate the surface changes that occurred during the testing.

The breakdown potential of the stainless steel bracket, stainless steel wire, NiTi wire, and TMA wires were $200 \mathrm{mv}, 600 \mathrm{mv}, 1600 \mathrm{mv}$, and >2000mv respectively. When coupled with a stainless steel bracket, all wire types yielded a breakdown potential of 200mv. The results indicated that regardless of the type of wire engaged in the slot of a stainless steel bracket, the breakdown occurred at the point where the stainless steel bracket would have corroded if tested alone. The bracket was the weak link and reached its breakdown point equally early in all of the samples tested. When 
tested alone, the most corrosion resistant wires were the TMA wires. TMA could be a suitable alternative in treating nickel sensitive patients. In addition, gold coating seemed to protect the underlying stainless steel wires from their characteristic corrosion tendency. This type of wire might also be considered when treating a patient with a severe nickel allergy. However, the predominating factor appears to be the stainless steel bracket which breaks down readily and will leach nickel ions into the oral cavity. If the orthodontist is truly concerned about a nickel allergy, an alternative appliance system should be employed such as ceramic, polycarbonate or gold brackets.

Surface evaluation revealed significant discoloration and pitting in all of the samples except TMA and 24k gold-coated wires. Other studies in the literature indicate irregularities and internal stresses may influence corrosion resistance of metals with similar compositions. Therefore, metals with more irregularities and internal stresses would be more prone to corrosion breakdown. This may be one reason that the stainless steel bracket yielded the lowest breakdown value and controlled the corrosion properties of the coupled samples.

Further research could include investigation of the surface characteristics of these alloys after intraoral use versus when subjected to potentiostatic anodic polarization. Conducting experiments in a dynamic system may increase corrosion potential from the formation of localized areas of wear and disruption of the passive film layer. Simple bends placed in an archwire could affect its resistance to corrosion; especially when bending a gold coated wire. Analysis of the solution after anodic polarization may yield some interesting results. The amount and types of elements present would give an indication of the possible alloys to be avoided for use in certain 
patients. The $\mathrm{pH}$ of the solution may have a marked effect on the corrosion resistance of metals and yield strong clinical applications. Finally, SEM photographs could be taken of orthodontic appliances after use intraorally to evaluate surface characteristics. 


\section{REFERENCES}

1. Fisher AA. Contact dermititis. Philadelphia: Lae and Febiger, 1973: pg. 2

2. Grandjean P. Human exposure to nickel. IARC Sci Publ. 1984:53 : 469-85

3. Gawkrodger DJ, et al. Contact clinic survey of nickel sensitive subjects. Contact Dermitiyis 1986; 14: 165-9

4. Schubert H., et al. Epidemiology of nickel allergy. Contact Dermititis. 1987; 16: $122-8$

5. Rystedt I, Fisher T. Relationship between nickel and cobalt sensitization in hard metal workers. Contact Dermititis. 1983; 9: 195-200

6. McDonagh AJ, et al. Nickel sensitivity: the influence of ear piercing and atopy. Brit J Derm. 1992; 126: 16-8

7. Olumide YM. Contact dermititis in Nigeria. Contact Dermititis. 1985; 12: 2416

8. Council on Dental Materials, Instruments, and Equipment. Biological effects of nickel-containing dental alloys, J Am Dent Assn 1982; 501-5

9. Blanco-Dalmaul, Carrasquillo-Alberty H, Silva-parra J. A study of nickel allergy. J Pros Dent. 1984;52(1):116-9

10. Jones TK, et al. Dental implications of nickel hypersensitivity. J Pros Dent:1986;56(4):507-9

11. Gretchen JB, Hall WB. Nickel hypersensitivity-related periodontitis. Compendium. 1995;16:178-84

12. Dunlap CL, Vincent K, Barker BF. Allergic reaction to orthodontic wire: report of caes. J Am Dent Association 1989; 118:449-50

13. Bass JK, Fine H, Cisneros J. Nickel hypersensitivity in the orthodontic patient. Am J Orthod. 1993;103(3):280-5 
14. Feasby WH, Ecclestone ER, Grainger RM. Nickel sensitivity in pediatric dental patients. Ped. Dent. 1988;10(2):127-29

15. Hurst CL, et. al. An evaluation of the shape memory phenomenom of nickel titanium wires. Am J Orthod. 1990;98(1):72-6

16. Rostoker W, Pretzel CW, Galante JO. Couple corrosion among alloys for skeletal prostheses. J Biomed Mater Res. 1974;8:407

17. Edie JW, Andreasen GF, Zaytoun MP. Surface corrosion of nitinol and stainless steel under clinical conditions. Angle Orthod. 1981;51:319-24

18. Park HY, Shearer TR. In vitro release of nickel and chromium from simulated orthodontic appliances. AM J Orthod. 1983;84:156-9

19. Grimsdottir MR, Gjerdet NR, Hensten-Pettersen A. Composition and in vitro corrosion of orthodontic appliances. Am J Orthod. 1992;101(6):525-32

20. Kerosuo H, Moe G, Kleven E. In vitro release of nickel and chromium from different types of simulated orthodontic appliances. Angle Orthod.1995;56(2):111-6

21. Sarkar NK, et al. In vivo and in vitro corrosion products of dental amalgam. J Dent Res. 1975;54:1031

22. Sarkar NK, et al. The chloride corrosion behavior of four orthodontic wires. $\mathbf{J}$ Dent Res. (Supplemental Issue A). 1979;53:98

23. Hoar TP, Mears DC. Corrosion-resistant alloys in chloride solutions: materials for surgical implants. Proc Roy Soc Ser A. 1966;294(1439):486

24. Solar RJ. An in vitro investigation of the corrosion and capacitative behavior of titanium surgical implant alloys. PhD. Thesis; Univ. of Penn. 1977

25. Sedriks AJ, Green JA, Novak DL. Electrochemical behavior of NiTi alloys in acidic chloride solutions. Corrosion. 1972;28:137-42

26. Speck KM, Fraker AC. Anodic polarization behavior of NiTi and Ti-6A1-4V in simulated physiological solution. J Dent Res. 1980;59:1590-95

27. Scully JC. The Fundamentals of Corrosion. New York: Pergamon Press Inc., 1975:112-30

28. Revie RW, Greene ND. Comparison of the in vitro and in vivo corrosion of 18-8 stainless steel and titanium. J Biomedical Mat Res. 1969;3:465 
29. Solar RJ, Korostoff E, Pollack SR. Corrosion resistance of Ti 6A1-4V in ringer's solution with selected amino acids. IADR progr and abst. 1976;55:No 130

30. Sarkar NK, Greener EH. In vitro corrosion resistance of new dental alloys. Biomat, Med Dev, Art Org. 1973;1(1):121

31. Greene ND. The classical potentiostat: its application to the study of passivity. Corrosion. 1959; 15(7):269

32. Dean SW Jr, France WD Jr, Ketcham SJ. Electrochemical methods in Handbook on Corrosion Testing and Evaluation. Ailor WH (Ed). New York: Wiley, 1971:192

33. Greene ND. Predicting behavior of corrosion resistant alloys by potentiostatic polarization methods. Corrosion. 1962;18:136t

34. Mueller H, Greener E. Polarization studies of surgical implant materials in Ringer's solution. J Biomed Mat Res. 1970;4:29

35. Platt J, Guzman A, Zuccari A, Thornburg D, Rhodes B, Oshida Y, Moore K,. Corrosion behavior of 2205 duplex stainless steel. Am J Orth 1997;112:69-79.

36. Pourbaix M. Atlas of electrochemical Equilibria in Aqueous Solutions. New York: Pergamon Press Inc, 1966.

37. Fontana M, Greene N. Corrosion Engineering. New York: McGraw-Hill, 1967:313

38. Schwabe K. The passivity of metals. Proc III Int Cong Met Corr. Vol. 1, Moscow, 1966, "Mir", 1969:52

39. Uhlig HH. Corrosion and Corrosion Control. New York: Wiley, 1971:60

40. Hoar TP. The production and breakdown of the passivity of metals. Proc III Int Met Corr. Vol. 1, Moscow, 1966, "Mir", 1969:88

41. Evans UR. The mechanism of corrosion. J Chem Soc. 1929:111

42. Schwanninger B, Sarkar NK, Foster BE. Effect of long-term immersion corrosion on the flexural properties of nitinol. Am J Orthod. 1982;82:45-9

43. Harris EF, Newman SM, Nicholson JA. Nitinol archwire in a simulated oral environment: Changes in mechanical properties. Am J Orthod. 1988;93(6):50813 
44. Kim H, Johnson J, Corrosion of stainless steel, nickel titanium, and TMA orthodontic wires. Angle Orthodontist; in press.

45. Menaker L. The Biological Basis of Dental Caries. Hagerstown: Harper and Row, 1980: 138,215

46. Greer KW, Luckey HA. Corrosion characteristics of Ti-6A1-4v ELI in orthopedic devices. Presented at MATCON'74, ASM/TMS-AIME. Detroit, Oct. 22, 1974

47. Revie RW, Greene ND. Corrosion behavior of surgical implant material: I. Effects of surface preparation. Corr Sci. 1969;9:755

48. Revie RW, Greene ND. Corrosion behavior of surgical implant material: I. Effects of sterilization. Corr Sci 1969;9:755

49. Levy M, et al. The corrosion behavior of titanium alloys in chloride solutions: materials for surgical implants. Publ No. AD 753 573, NTIS, U.S. Dept of Commerce. 1972

50. Dumbleton JH, Miller EH. Failure of metallic orthopedic implants. Failure Analysis and Prevention, Metals Handbook, Vol. 10, $8^{\text {th }}$ ed. ASM, 1975:571

51. Fraker AC, Ruff AW, Yeager MP. Corrosion of titanium alloys in physiological solutions. Proc $2^{\text {nd }}$ Int Ti conf, Boston, 1972. New York: Plenus Press, 1973

52. Standard reference test method for making potentiostatic and potentiodynamic anodic polarization measurements. ASTM G5-94, American Society for Testing and Materials. Philadelphia. 1994;3.02:48-58

53. Burstone CJ, Farzin-Nia F. Production of low-friction and colored TMA by ion implantation. J Clin Orthod. 1995;29:453-61 


\section{APPENDIX}

\section{Potentiostatic Anodic Polarization Data}




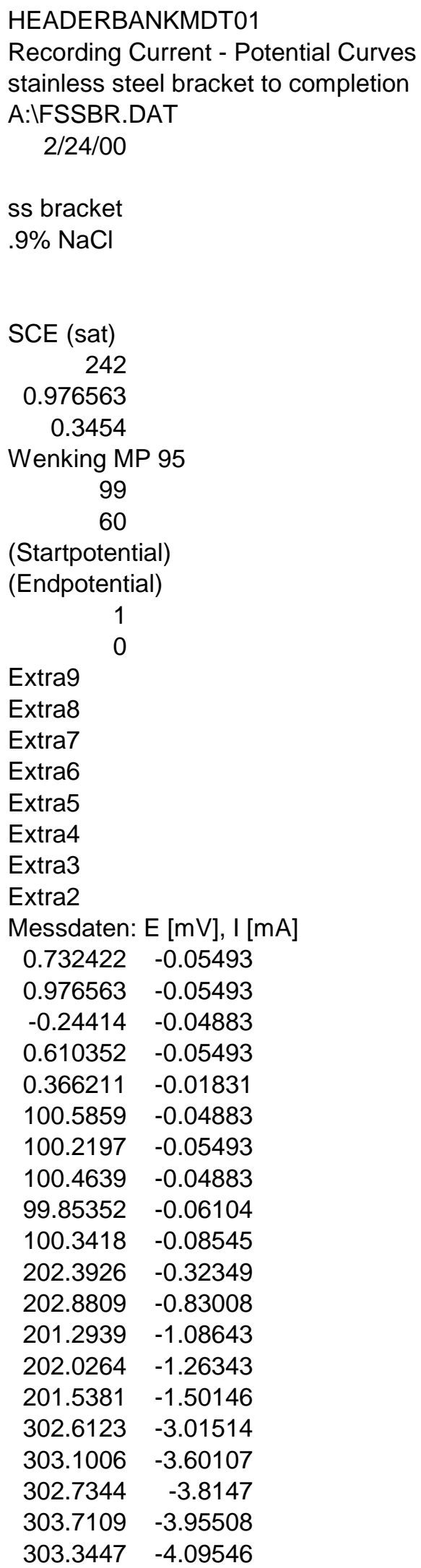




\begin{tabular}{rr}
405.5176 & -5.52979 \\
406.0059 & -5.76782 \\
404.6631 & -5.85327 \\
405.3955 & -5.9082 \\
406.25 & -5.95703 \\
405.0293 & -6.073 \\
403.6865 & -6.13403 \\
405.2734 & -6.12793 \\
405.3955 & -6.12793 \\
405.5176 & -6.15845 \\
405.0293 & -6.15234 \\
404.541 & -6.18286 \\
503.9063 & -7.55615 \\
503.9063 & -7.58057 \\
503.9063 & -7.48901 \\
503.1738 & -7.48901 \\
602.2949 & -8.72803 \\
602.7832 & -8.91113 \\
602.2949 & -8.71582 \\
603.2715 & -8.64868 \\
603.1494 & -8.49609 \\
602.7832 & -7.87354 \\
701.6602 & -7.73315 \\
701.6602 & -7.94067 \\
701.6602 & -7.83691 \\
702.6367 & -6.39038 \\
713.8672 & -7.49512 \\
801.7578 & -1.88599 \\
800.9033 & -1.87378 \\
802.6123 & -5.01099 \\
800.5371 & -1.81885 \\
801.2695 & -6.0791 \\
901.8555 & -9.76563 \\
901.7334 & -10.1135 \\
901.9775 & -10.4919 \\
901.7334 & -10.5469 \\
1001.953 & -12.6648 \\
1001.709 & -14.7766 \\
1000.854 & -14.5203 \\
1099.243 & -15.1428 \\
1099.854 & -17.6575 \\
1098.755 & -16.3879 \\
1098.633 & -15.7043 \\
1099.365 & -17.1753 \\
1199.585 & -18.0237 \\
1199.829 & -18.2495 \\
1298.706 & -19.9951 \\
1297.974 & -20.0806 \\
1296.753 & -20.0928 \\
\hline & -20.4163 \\
\hline & -21.3928
\end{tabular}




$\begin{array}{rr}1299.194 & -21.46 \\ 1298.584 & -21.7957 \\ 1397.095 & -23.5352 \\ 1397.095 & -21.9421 \\ 1398.193 & -21.936 \\ 1396.973 & -21.936 \\ 1397.583 & -21.8506 \\ 1397.583 & -21.8506 \\ 1501.587 & -23.5657 \\ 1501.709 & -23.8342 \\ 1501.587 & -23.9075 \\ 1500.61 & -24.0784 \\ 1501.099 & -24.3713 \\ 1501.099 & -24.6216 \\ 1595.947 & -25.4028 \\ 1595.947 & -26.2695 \\ 1696.777 & -26.8311 \\ 1696.777 & -26.3062 \\ 1696.533 & -26.8738 \\ 1696.655 & -26.8188 \\ 1697.388 & -27.0935 \\ 1796.265 & -28.0762 \\ 1796.753 & -28.2837 \\ 1795.532 & -27.7283 \\ 1898.926 & -28.3569 \\ 1898.438 & -29.0283 \\ 1898.315 & -28.5461 \\ 2002.686 & -28.9978\end{array}$

\section{HEADERBANKMDT01}

Recording Current - Potential Curves
A:ISSB1.DAT
$1 / 31 / 99$
O'Leary
s.s. bracket
$.9 \%$ saline
7
room
SCE (sat)
242
0.854492
0.3454
Wenking MP 95
60
60
(Startpotential)
(Endpotential)

1

0 


\begin{aligned} & Extra9 \\ & Extra8 \\ & Extra7 \\ & Extra6 \\ & Extra5 \\ & Extra4 \\ & Extra3 \\ & Extra2 \\ & Messdaten: E [mV], I [mA] \\ & 0.854492-0.05493 \\ & 0.732422-0.05493 \\ & 1.220703-0.04883 \\ & 0.854492-0.06104 \\ & 0.732422-0.04883 \\ & 0.732422-0.05493 \\ & 100.0977-0.06104 \\ & 100.2197-0.06104 \\ & 100.5859-0.06104 \\ & 100.2197-0.06104 \\ & 100.2197-0.06104 \\ & 201.2939-0.12207 \\ & 201.416-0.06104 \\ & 201.9043-0.06104 \\ & 201.6602-0.06104 \\ & 201.416-0.04883 \\ & 305.7861-0.06104 \\ & 305.6641-0.05493 \\ & 305.1758-0.05493 \\ & 305.4199-0.05493 \\ & 305.1758-0.06104 \\ & 402.5879-0.05493 \\ & 403.3203-0.05493 \\ & 402.9541-0.06104 \\ & 402.71-0.06104 \\ & 402.832-0.06104 \\ & 503.418-0.06104 \\ & 503.2959-0.06104 \\ & 503.6621-0.06104 \\ & 503.9063-0.06104 \\ & 504.0283-0.06104 \\ & 601.4404-0.06104 \\ & 601.5625-0.07935 \\ & 600.8301-0.09155 \\ & 600.8301-0.24414 \\ & 601.5625-0.06104 \\ & 601.3184-0.06104 \\ & 701.6602-0.07935 \\ & 701.6602-0.10986 \\ & 702.0264-0.10376 \\ & 700.8057-0.12207 \\ & 700.8057-0.12207 \\ & \\ & \hline\end{aligned}




$\begin{array}{rr}802.6123 & -0.177 \\ 803.833 & -0.24414 \\ 802.6123 & -0.22583 \\ 802.2461 & -7.32422 \\ 802.7344 & -6.05469 \\ 900.7568 & -10.7422 \\ 900.6348 & -11.9019 \\ 900.8789 & -0.79346 \\ 901.3672 & -0.79346 \\ 901.2451 & -1.09863 \\ 997.6807 & -14.4653 \\ 997.6807 & -19.4824 \\ 997.5586 & -22.2168 \\ 997.4365 & -22.7661 \\ 997.1924 & -23.1812 \\ 1097.778 & -25.0244 \\ 1097.656 & -25.2075 \\ 1098.022 & -25.2686\end{array}$

HEADERBANKMDT01

Recording Current - Potential Curves

stainless steel wire

A:ISSB2.DAT

2/2/00

Ss bracket

$.9 \% \mathrm{NaCl}$

SCE (sat)

242

0.610352

0.3454

Wenking MP 95

30

60

(Startpotential)

(Endpotential)

\begin{tabular}{|c|c|}
\hline $\begin{array}{l}1 \\
0\end{array}$ & \\
\hline Extra9 & \\
\hline Extra8 & \\
\hline Extra7 & \\
\hline Extra6 & \\
\hline Extra5 & \\
\hline Extra4 & \\
\hline Extra3 & \\
\hline Extra2 & \\
\hline Messdaten & $\mathrm{E}[\mathrm{mV}], \mathrm{I}[\mathrm{mA}]$ \\
\hline 0.854492 & -0.04272 \\
\hline 0.366211 & -0.02441 \\
\hline
\end{tabular}




$\begin{array}{rr}0.244141 & -0.01831 \\ 1.220703 & -0.11597 \\ 1.953125 & -0.09766 \\ 98.63281 & -0.03662 \\ 100.3418 & -0.03662 \\ 99.73145 & -0.04883 \\ 98.51074 & -0.14648 \\ 100.0977 & -0.09766 \\ 205.3223 & -0.25024 \\ 204.9561 & -0.43335 \\ 204.9561 & -0.57373 \\ 205.0781 & -0.7019 \\ 205.5664 & -0.83618 \\ 304.4434 & -1.7395 \\ 304.0771 & -2.18506 \\ 303.5889 & -2.50854 \\ 303.833 & -2.70996 \\ 304.3213 & -2.88696 \\ 404.2969 & -4.15649 \\ 404.2969 & -4.41895 \\ 403.8086 & -4.63257 \\ 404.1748 & -4.92554 \\ 404.9072 & -5.13916 \\ 503.0518 & -6.5918 \\ 501.709 & -6.92139 \\ 502.8076 & -7.1167 \\ 502.4414 & -7.22046 \\ 602.7832 & -8.99048\end{array}$

HEADERBANKMDT01

Recording Current - Potential Curves stainless steel bracket

A:ISSB3.DAT

$2 / 2 / 00$

ss bracket

$.9 \% \mathrm{NaCl}$

SCE (sat)

242

0.610352

0.3454

Wenking MP 95

36

60

(Startpotential)

(Endpotential)

1

0

Extra9 


$\begin{array}{ll}\text { Extra8 } & \\ \text { Extra7 } & \\ \text { Extra6 } & \\ \text { Extra5 } & \\ \text { Extra4 } & \\ \text { Extra3 } & \\ \text { Extra2 } & \\ \text { Messdaten: } & \text { [mV], I [mA] } \\ 0.244141 & -0.03052 \\ 0.610352 & -0.03662 \\ 0.488281 & -0.04883 \\ 0.732422 & -0.03662 \\ 0.488281 & -0.04883 \\ 101.8066 & -0.08545 \\ 101.1963 & -0.10986 \\ 101.5625 & -0.09766 \\ 101.3184 & -0.10986 \\ 101.8066 & -0.12817 \\ 101.1963 & -0.10376 \\ 201.6602 & -0.40283 \\ 201.416 & -0.59204 \\ 201.2939 & -0.65918 \\ 201.6602 & -0.74463 \\ 202.1484 & -0.83008 \\ 301.8799 & -1.69067 \\ 302.002 & -1.88599 \\ 302.4902 & -2.02026 \\ 302.8564 & -2.06299 \\ 400.3906 & -2.92358 \\ 400.8789 & -3.1311 \\ 400.7568 & -3.17383 \\ 400.7568 & -3.26538 \\ 400.8789 & -3.38135 \\ 499.0234 & -4.41895 \\ 498.4131 & -4.70581 \\ 498.9014 & -4.85229 \\ 498.7793 & -4.93774 \\ 498.291 & -5.10254 \\ 602.0508 & -6.28662 \\ 602.7832 & -6.37207 \\ 601.5625 & -6.70776 \\ 601.8066 & -6.80542 \\ 601.9287 & -6.78101 \\ 698.1201 & -7.87964 \\ & \end{array}$

HEADERBANKMDT01

Recording Current - Potential Curves ss \#2 $50 \mathrm{mv} / 5 \mathrm{~min}$

A:ISSW1.DAT

$1 / 31 / 00$ 


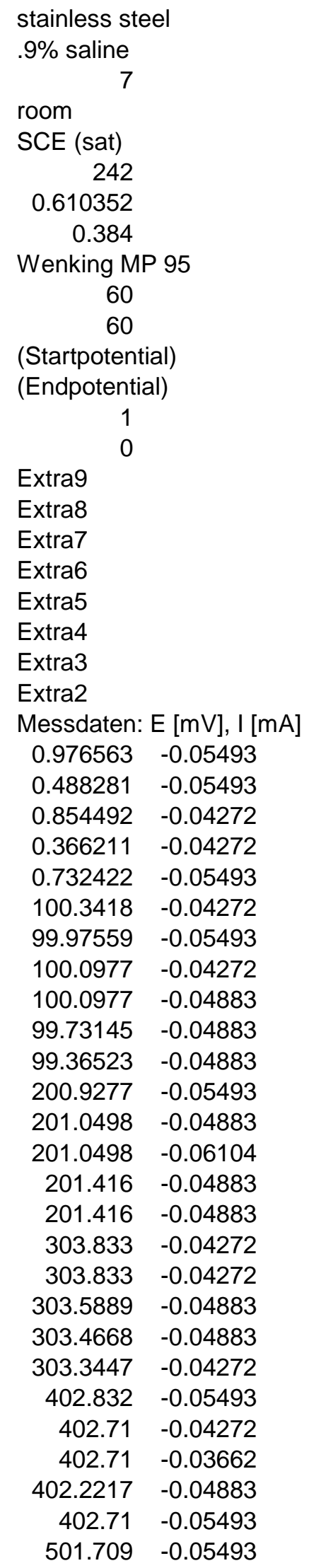




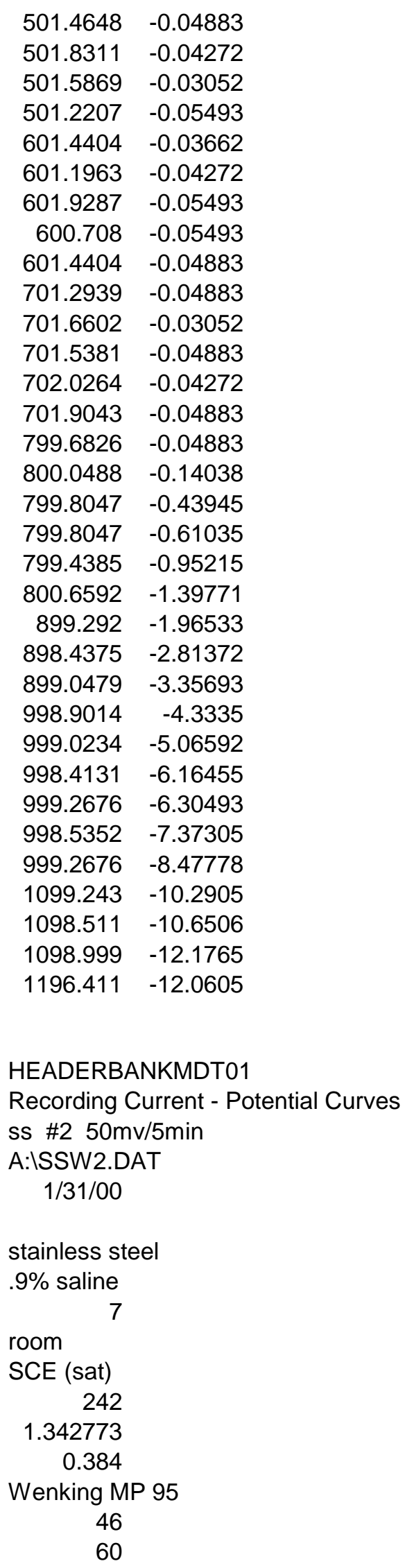


(Startpotential)

(Endpotential)

1

0

Extra9

Extra8

Extra7

Extra6

Extra5

Extra4

Extra3

Extra2

Messdaten: $E$ [mV], I [mA]

$1.342773-0.04883$

$0.610352-0.03662$

$0.854492-0.04272$

$0.366211-0.04272$

$0.976563-0.03662$

$99.4873-0.04272$

$99.36523-0.05493$

$99.4873-0.04883$

$99.12109-0.03052$

$99.12109-0.05493$

$199.707-0.05493$

$199.707-0.05493$

$199.8291-0.04272$

$199.9512-0.04272$

$199.8291-0.05493$

$301.5137-0.04883$

$301.3916-0.05493$

$301.1475-0.06104$

$301.2695-0.05493$

$301.2695-0.04272$

$402.71-0.05493$

$402.832-0.06104$

$402.9541-0.06104$

$402.5879-0.05493$

$402.9541-0.04272$

$504.5166-0.04272$

$504.2725 \quad-0.06104$

$503.9063-0.03662$

$504.8828-0.04883$

$505.249-0.04272$

$601.9287-0.55542$

$601.9287-2.20337$

$602.417 \quad-3.36304$

$602.1729-4.09546$

$601.9287 \quad-5.15747$

$703.8574-8.42896$

$703.2471-10.1746$

$703.4912-11.7981$ 


$\begin{array}{rr}703.125 & -11.8835 \\ 702.2705 & -13.0737 \\ 800.9033 & -16.7236 \\ 800.7813 & -17.5598 \\ 800.293 & -18.4387 \\ 800.9033 & -19.7571 \\ 900.6348 & -23.0713 \\ 900.2686 & -24.231\end{array}$

HEADERBANKMDT01

Recording Current - Potential Curves

\section{A:INITIW1.DAT 2/3/99}

niti wire 1

.9 nacl

SCE (sat)

242

1.342773

0.384

Wenking MP 95

109

60

(Startpotential)

(Endpotential)

\begin{tabular}{ll}
\multicolumn{2}{c}{1} \\
Extra9 \\
Extra8 \\
Extra7 \\
Extra6 & \\
Extra5 & \\
Extra4 & \\
Extra3 & \\
Extra2 & \\
Messdaten: & E [mV], I [mA] \\
0.854492 & -0.06104 \\
1.098633 & -0.04883 \\
0.976563 & -0.04883 \\
0.610352 & -0.04272 \\
0.854492 & -0.04272 \\
1.342773 & -0.04272 \\
102.7832 & -0.04272 \\
103.5156 & -0.04272 \\
102.7832 & -0.03052 \\
102.9053 & -0.03662 \\
103.5156 & -0.04272 \\
201.416 & -0.04883
\end{tabular}




$\begin{array}{rr}200.9277 & -0.04272 \\ 201.1719 & -0.04272 \\ 201.0498 & -0.04272 \\ 200.9277 & -0.04883 \\ 305.4199 & -0.03662 \\ 305.6641 & -0.04272 \\ 305.542 & -0.03662 \\ 305.4199 & -0.03662 \\ 305.4199 & -0.03662 \\ 403.0762 & -0.03662 \\ 401.9775 & -0.03052 \\ 402.5879 & -0.04272 \\ 402.5879 & -0.04272 \\ 402.71 & -0.04272 \\ 502.6855 & -0.04272 \\ 502.3193 & -0.04883 \\ 502.6855 & -0.04272 \\ 503.1738 & -0.04883 \\ 502.5635 & -0.04272 \\ 602.1729 & -0.04272 \\ 602.2949 & -0.03662 \\ 602.0508 & -0.02441 \\ 601.9287 & -0.03662 \\ 601.9287 & -0.03662 \\ 601.5625 & -0.03052 \\ 704.5898 & -0.04272 \\ 705.0781 & -0.04272 \\ 705.2002 & -0.04883 \\ 704.7119 & -0.04883 \\ 704.4678 & -0.04883 \\ 801.6357 & -0.03052 \\ 802.124 & -0.03052 \\ 801.7578 & -0.04272 \\ 802.002 & -0.04272 \\ 801.8799 & -0.04272 \\ 900.7568 & -0.04272 \\ 899.9023 & -0.02441 \\ 899.9023 & -0.04883 \\ 900.2686 & -0.03662 \\ 900.3906 & -0.04272 \\ 998.9014 & -0.03662 \\ 999.1455 & -0.04272 \\ 999.7559 & -0.03662 \\ 999.5117 & -0.03052 \\ 998.9014 & -0.05493 \\ 1098.511 & -0.03662 \\ 1098.389 & -0.03052 \\ 1098.999 & -0.04272 \\ 1099.121 & -0.04272 \\ 1098.755 & -0.03052 \\ 1199.341 & -0.04272\end{array}$




$\begin{array}{rr}1199.341 & -0.03662 \\ 1198.975 & -0.03052 \\ 1199.219 & -0.04272 \\ 1199.341 & -0.02441 \\ 1199.463 & -0.04272 \\ 1299.683 & -0.03662 \\ 1299.561 & -0.04272 \\ 1300.049 & -0.04272 \\ 1300.049 & -0.04883 \\ 1299.561 & -0.04272 \\ 1299.927 & -0.04272 \\ 1397.217 & -0.02441 \\ 1397.217 & -0.03662 \\ 1397.095 & -0.04883 \\ 1397.339 & -0.04883 \\ 1397.339 & -0.03662 \\ 1496.704 & -0.05493 \\ 1497.07 & -0.05493 \\ 1496.826 & -0.05493 \\ 1496.948 & -0.05493 \\ 1497.07 & -0.06714 \\ 1596.68 & -0.177 \\ 1596.924 & -0.23804 \\ 1596.924 & -0.29297 \\ 1596.558 & -0.354 \\ 1597.29 & -0.39673 \\ 1697.388 & -1.42212 \\ 1697.632 & -1.89819 \\ 1697.266 & -2.13623 \\ 1697.021 & -2.34375 \\ 1697.144 & -2.53906 \\ 1796.509 & -5.05981 \\ 1796.509 & -5.82886 \\ 1796.509 & -5.91431 \\ 1795.776 & -5.99365 \\ 1796.509 & -5.94482 \\ 1796.387 & -5.98145 \\ 1899.292 & -9.96094 \\ 1899.17 & -9.82666 \\ 1898.682 & -9.63745 \\ 1899.536 & -9.42993 \\ 1899.292 & -9.31396 \\ 1999.878 & -13.5376 \\ 2000.122 & -13.4705 \\ 2000 & -13.4033 \\ 2000.366 & -13.3118\end{array}$

HEADERBANKMDT01

Recording Current - Potential Curves

A:INITIW2.DAT 


\section{$2 / 3 / 00$}

niti wire 2

.9 nacl

SCE (sat) 242

0.854492

0.384

Wenking MP 95

98

60

(Startpotential)

(Endpotential)

1

0

Extra9

Extra8

Extra7

Extra6

Extra5

Extra4

Extra3

Extra2

Messdaten: $E$ [mV], I [mA]

$0.854492-0.04272$

$0.366211-0.05493$

$0.610352-0.05493$

$0.732422-0.04272$

$0.976563-0.04272$

$0.854492-0.03662$

$100.9521-0.05493$

$100.2197-0.05493$

$100.4639-0.05493$

$100.3418-0.06104$

$100.4639-0.04883$

$199.3408-0.04272$

$199.9512-0.03052$

$200.3174-0.04883$

$200.0732-0.03662$

$200.1953-0.05493$

$301.2695-0.04272$

$301.2695-0.03662$

$301.1475-0.04883$

$301.7578-0.03662$

$300.7813-0.04883$

$400.0244-0.04883$

$400.5127-0.03052$

$401.001-0.05493$

$399.9023-0.04883$ 


\begin{tabular}{rr}
400.5127 & -0.04883 \\
503.9063 & -0.04272 \\
504.0283 & -0.04272 \\
503.418 & -0.04272 \\
503.7842 & -0.03662 \\
503.9063 & -0.03662 \\
600.2197 & -0.06104 \\
600.3418 & -0.04272 \\
600.3418 & -0.02441 \\
600.3418 & -0.03662 \\
600.4639 & -0.04272 \\
599.8535 & -0.03052 \\
702.1484 & -0.04883 \\
702.5146 & -0.04883 \\
702.1484 & -0.03052 \\
702.0264 & -0.04883 \\
702.2705 & -0.04272 \\
798.8281 & -0.04272 \\
798.584 & -0.04272 \\
798.4619 & -0.03662 \\
798.584 & -0.03662 \\
898.6816 & -0.04883 \\
898.6816 & -0.04272 \\
898.9258 & -0.04883 \\
898.5596 & -0.04883 \\
898.6816 & -0.02441 \\
999.3896 & -0.04272 \\
999.7559 & -0.04272 \\
999.3896 & -0.03662 \\
999.6338 & -0.03662 \\
999.2676 & -0.04272 \\
1095.215 & -0.04272 \\
1095.215 & -0.04272 \\
1095.337 & -0.04272 \\
1095.459 & -0.04883 \\
1094.971 & -0.03662 \\
1196.289 & -0.04883 \\
1196.045 & -0.05493 \\
1196.045 & -0.03662 \\
1196.045 & -0.04883 \\
1195.801 & -0.04883 \\
1298.096 & -0.03662 \\
1298.096 & -0.05493 \\
1297.852 & -0.05493 \\
1297.974 & -0.04272 \\
1298.34 & -0.04272 \\
1396.484 & -0.03662 \\
1396.362 & -0.05493 \\
\hline 396.118 & -0.04272 \\
& -0.05493
\end{tabular}




$$
\begin{array}{rr}
1489.014 & -0.06104 \\
1499.023 & -0.06104 \\
1499.39 & -0.06104 \\
1499.756 & -0.06104 \\
1499.023 & -0.06104 \\
1598.022 & -0.10986 \\
1597.168 & -0.15259 \\
1597.534 & -0.19531 \\
1597.29 & -0.23804 \\
1596.802 & -0.26855 \\
1597.412 & -0.29907 \\
1694.946 & -1.26953 \\
1695.19 & -1.46484 \\
1695.19 & -1.60522 \\
1797.119 & -3.88184 \\
1798.218 & -4.26636 \\
1797.607 & -4.54712 \\
1797.363 & -4.67529 \\
1900.757 & -8.27637 \\
1998.169 & -11.7798 \\
1997.925 & -12.2986 \\
1997.681 & -12.4451
\end{array}
$$

HEADERBANKMDT01

Recording Current - Potential Curves

\section{A:INITIW3.DAT $2 / 3 / 00$}

niti wire 3

.9 nacl

$$
\begin{array}{r}
\text { SCE (sat) } \\
242 \\
0.732422 \\
0.384
\end{array}
$$

Wenking MP 95

93

60

(Startpotential)

(Endpotential)

1

0

Extra9

Extra8

Extra7

Extra6

Extra5

Extra4

Extra3 


\begin{aligned} & Extra2 \\ & Messdaten: $\mathrm{E}[\mathrm{mV}], \mathrm{I}[\mathrm{mA}] \\ & 1.342773-0.04883 \\ & 1.098633-0.06104 \\ & 0.854492-0.05493 \\ & 1.098633-0.05493 \\ & 1.220703-0.06104 \\ & 102.6611-0.05493 \\ & 102.7832-0.05493 \\ & 102.6611-0.04272 \\ & 102.6611-0.05493 \\ & 102.5391-0.03052 \\ & 102.2949-0.05493 \\ & 203.8574-0.05493 \\ & 204.3457-0.02441 \\ & 204.4678-0.05493 \\ & 204.2236-0.02441 \\ & 204.4678-0.04883 \\ & 302.2461-0.05493 \\ & 302.2461-0.01831 \\ & 302.124-0.04883 \\ & 301.7578-0.03662 \\ & 402.71-0.04272 \\ & 402.4658-0.05493 \\ & 402.832-0.01831 \\ & 402.832-0.06104 \\ & 402.832-0.06104 \\ & 500-0.04272 \\ & 500.7324-0.01831 \\ & 500.6104-0.03662 \\ & 500.2441-0.06104 \\ & 500.9766-0.06104 \\ & 602.1729-0.02441 \\ & 601.6846-0.05493 \\ & 601.5625-0.04883 \\ & 600.9521-0.03662 \\ & 704.3457-0.01831 \\ & 704.7119-0.04272 \\ & 704.7119-0.03662 \\ & 704.7119-0.04883 \\ & 705.2002-0.04883 \\ & 799.6826-0.04883 \\ & 799.8047-0.04272 \\ & 799.9268-0.04272 \\ & 799.0723-0.03662 \\ & 799.6826-0.04272 \\ & 799.6826-0.03662 \\ & 900.5127-0.04272 \\ & 900.3906-0.02441 \\ & 900.6348-0.05493 \\ & 900.2686-0.04272 \\ & \\ &$\hline\end{aligned}




$\begin{array}{rr}900.3906 & -0.05493 \\ 999.8779 & -0.04883 \\ 999.7559 & -0.05493 \\ 999.6338 & -0.06104 \\ 1000 & -0.05493 \\ 1099.243 & -0.03662 \\ 1099.487 & -0.04883 \\ 1099.609 & -0.04883 \\ 1099.487 & -0.06104 \\ 1098.633 & -0.05493 \\ 1099.487 & -0.04272 \\ 1200.684 & -0.04272 \\ 1200.439 & -0.03662 \\ 1200.195 & -0.04883 \\ 1199.829 & -0.03662 \\ 1199.707 & -0.03662 \\ 1298.828 & -0.05493 \\ 1298.95 & -0.04883 \\ 1298.828 & -0.04272 \\ 1298.34 & -0.03662 \\ 1299.072 & -0.04883 \\ 1398.438 & -0.06104 \\ 1397.827 & -0.06104 \\ 1398.315 & -0.04272 \\ 1397.461 & -0.03052 \\ 1397.705 & -0.03662 \\ 1499.512 & -0.05493 \\ 1500 & -0.04272 \\ 1500.244 & -0.06104 \\ 1499.878 & -0.05493 \\ 1500.122 & -0.06104 \\ 1595.581 & -0.14648 \\ 1595.337 & -0.12817 \\ 1595.093 & -0.18311 \\ 1595.459 & -0.18311 \\ 1595.581 & -0.23804 \\ 1695.923 & -1.10474 \\ 1696.167 & -1.28174 \\ 1696.533 & -1.44043 \\ 1796.509 & -3.54614 \\ 1795.776 & -3.66211 \\ 1899.17 & -6.57349 \\ 1899.292 & -6.9519 \\ 2002.808 & -10.8826\end{array}$

HEADER HEADER HEADERBANKMDTO

BANKMD BANKMD 3

T01 T02

Recording Current - Potential Curves

\section{A:ITMAW1.DAT}


tma wire 1

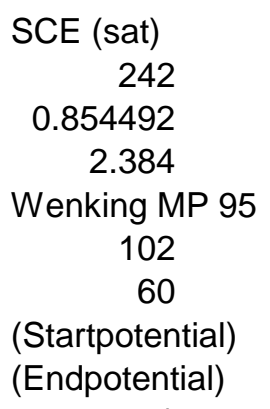




$\begin{aligned} 501.5869 & -0.03662 \\ 501.709 & -0.04272 \\ 501.8311 & -0.04272 \\ 501.8311 & -0.03662 \\ 501.8311 & -0.02441 \\ 602.2949 & -0.03662 \\ 602.417 & -0.03052 \\ 602.5391 & -0.05493 \\ 602.2949 & -0.03662 \\ 602.5391 & -0.03052 \\ 602.417 & -0.04272 \\ 703.7354 & -0.04883 \\ 703.4912 & -0.04272 \\ 703.3691 & -0.03662 \\ 703.0029 & -0.03052 \\ 703.7354 & -0.03052 \\ 801.0254 & -0.02441 \\ 801.3916 & -0.04272 \\ 801.7578 & -0.03662 \\ 801.1475 & -0.04883 \\ 801.2695 & -0.03662 \\ 899.9023 & -0.04272 \\ 899.292 & -0.03662 \\ 899.1699 & -0.04883 \\ 899.0479 & -0.04272 \\ 899.6582 & -0.04272 \\ 899.4141 & -0.03662 \\ 999.2676 & -0.04883 \\ 999.1455 & -0.03052 \\ 998.7793 & -0.04883 \\ 998.6572 & -0.04272 \\ 1097.29 & -0.03662 \\ 1097.29 & -0.03662 \\ 1096.802 & -0.03662 \\ 1097.29 & -0.04272 \\ 1096.924 & -0.03052 \\ 1195.435 & -0.04883 \\ 1197.144 & -0.04272 \\ 1196.167 & -0.03662 \\ 1197.144 & -0.04883 \\ 1196.533 & -0.03662 \\ 1298.462 & -0.05493 \\ 1298.34 & -0.04272 \\ 1298.706 & -0.05493 \\ 1297.974 & -0.04272 \\ 1298.218 & -0.04883 \\ 1394.653 & -0.04272 \\ 1394.531 & -0.04272 \\ 1394.653 & -0.03662 \\ 1395.02 & -0.04272 \\ 1495.605 & -0.04272\end{aligned}$




$\begin{array}{rr}1495.483 & -0.03662 \\ 1495.605 & -0.04272 \\ 1495.483 & -0.03662 \\ 1495.361 & -0.04272 \\ 1593.384 & -0.05493 \\ 1593.018 & -0.04272 \\ 1593.262 & -0.03662 \\ 1593.14 & -0.03662 \\ 1593.384 & -0.04272 \\ 1698.608 & -0.04272 \\ 1698.73 & -0.03662 \\ 1698.975 & -0.03662 \\ 1698.486 & -0.03662 \\ 1698.364 & -0.04272 \\ 1797.119 & -0.03662 \\ 1797.119 & -0.04272 \\ 1796.875 & -0.03662 \\ 1796.631 & -0.03662 \\ 1797.241 & -0.03662 \\ 1898.193 & -0.03662 \\ 1897.827 & -0.03662 \\ 1897.949 & -0.03662 \\ 1897.705 & -0.04272 \\ 1898.193 & -0.03052 \\ 2000.366 & -0.04272 \\ 2001.099 & -0.04272\end{array}$

HEADERBANKMDT01

Recording Current - Potential Curves

\section{A:ITMAW2.DAT \\ $2 / 4 / 00$}

tma wire 2

SCE (sat)
242
0.732422
0.384
Wenking MP 95
103
60
(Startpotential)
(Endpotential)
1
0
Extra9
Extra8
Extra7




\begin{aligned} & Extra6 \\ & Extra5 \\ & Extra4 \\ & Extra3 \\ & Extra2 \\ & Messdaten: E $[\mathrm{mV}], \mathrm{I}[\mathrm{mA}] \\ & 0.732422-0.03662 \\ & 1.464844-0.03662 \\ & 0.610352-0.04883 \\ & 0.732422-0.03662 \\ & 1.220703-0.04272 \\ & 0.854492-0.04883 \\ & 100.0977-0.03662 \\ & 100.4639-0.04883 \\ & 100.4639-0.03662 \\ & 100.708-0.03662 \\ & 100.2197-0.03662 \\ & 201.6602-0.03052 \\ & 201.6602-0.03052 \\ & 201.2939-0.03662 \\ & 201.6602-0.03662 \\ & 303.4668-0.03052 \\ & 303.3447-0.03662 \\ & 303.7109-0.03662 \\ & 303.4668-0.04272 \\ & 302.8564-0.04883 \\ & 303.7109-0.03662 \\ & 404.9072-0.04272 \\ & 404.9072-0.03052 \\ & 405.2734-0.04272 \\ & 404.541-0.04272 \\ & 405.1514-0.03052 \\ & 500.7324-0.04272 \\ & 500.7324-0.04883 \\ & 500.9766-0.04272 \\ & 500.7324-0.03662 \\ & 500.9766-0.03052 \\ & 604.0039-0.03052 \\ & 604.248-0.04883 \\ & 603.3936-0.03662 \\ & 603.7598-0.03662 \\ & 705.3223-0.03052 \\ & 705.0781-0.03662 \\ & 704.5898-0.04272 \\ & 705.5664-0.04883 \\ & 705.3223-0.03662 \\ & 802.6123-0.04272 \\ & 801.7578-0.03662 \\ & 802.3682-0.03052 \\ & 802.124-0.03662 \\ &-0.04272 \\ &$\hline\end{aligned}




$\begin{aligned} 904.541 & -0.03662 \\ 904.9072 & -0.03662 \\ 904.4189 & -0.04272 \\ 904.0527 & -0.03662 \\ 904.2969 & -0.03662 \\ 904.1748 & -0.03662 \\ 1000.488 & -0.04883 \\ 999.6338 & -0.04272 \\ 1000.122 & -0.04883 \\ 1000.61 & -0.03662 \\ 1100.098 & -0.03662 \\ 1100.22 & -0.03662 \\ 1099.854 & -0.04272 \\ 1100.098 & -0.04272 \\ 1099.976 & -0.04883 \\ 1100.098 & -0.03662 \\ 1196.411 & -0.03662 \\ 1196.899 & -0.03052 \\ 1196.777 & -0.03052 \\ 1197.144 & -0.03052 \\ 1197.144 & -0.04272 \\ 1296.631 & -0.04272 \\ 1296.875 & -0.04272 \\ 1296.509 & -0.03662 \\ 1296.631 & -0.03662 \\ 1296.997 & -0.04272 \\ 1397.583 & -0.04883 \\ 1397.705 & -0.03662 \\ 1397.583 & -0.03662 \\ 1397.339 & -0.04883 \\ 1396.973 & -0.03662 \\ 1501.831 & -0.03052 \\ 1502.441 & -0.04883 \\ 1502.075 & -0.05493 \\ 1502.075 & -0.04883 \\ 1597.656 & -0.03052 \\ 1597.534 & -0.04272 \\ 1596.924 & -0.04272 \\ 1597.29 & -0.03052 \\ 1597.29 & -0.04272 \\ 1694.58 & -0.03662 \\ 1695.557 & -0.03662 \\ 1694.946 & -0.03662 \\ 1695.068 & -0.03662 \\ 1695.068 & -0.02441 \\ 1797.363 & -0.04272 \\ 1797.363 & -0.04272 \\ 1797.241 & -0.03662 \\ 1797.852 & -0.04272 \\ 1797.852 & -0.04272 \\ 1898.56 & -0.04272\end{aligned}$




$$
\begin{array}{ll}
1898.804 & -0.04272 \\
1898.438 & -0.03662 \\
1898.071 & -0.04883 \\
1898.438 & -0.05493 \\
1999.634 & -0.04272 \\
1999.268 & -0.04883 \\
1998.901 & -0.03662
\end{array}
$$

\section{HEADERBANKMDT01}

Recording Current - Potential Curves stainless steel wire 1 and ss bracket A:ISSC1.DAT

$$
2 / 8 / 00
$$

ss wire 1 and ss bracket $.9 \% \mathrm{NaCl}$

$$
\begin{array}{r}
\text { SCE (sat) } \\
242 \\
0.366211 \\
0.7294
\end{array}
$$

Wenking MP 95

35

60

(Startpotential)

(Endpotential)

1

0

Extra9

Extra8

Extra7

Extra6

Extra5

Extra4

Extra3

Extra2

Messdaten: E [mV], I [mA]

$0.488281-0.05493$

$0.610352-0.05493$

$0.854492-0.04272$

$\begin{array}{ll}0 & -0.03662\end{array}$

$\begin{array}{ll}0 & -0.05493\end{array}$

$0.976563-0.04272$

$99.85352-0.04883$

$99.24316-0.06104$

$99.4873-0.05493$

$99.73145-0.05493$

$203.9795-0.06104$

$203.4912-0.12207$ 


$\begin{array}{rr}204.2236 & -0.18311 \\ 204.2236 & -0.21973 \\ 203.4912 & -0.29907 \\ 303.1006 & -0.53101 \\ 302.4902 & -0.61646 \\ 302.6123 & -0.72632 \\ 302.8564 & -0.75073 \\ 302.6123 & -0.73242 \\ 401.8555 & -1.09863 \\ 401.2451 & -1.29395 \\ 401.6113 & -1.37939 \\ 401.6113 & -1.5625 \\ 402.3438 & -1.58691 \\ 501.2207 & -2.05688 \\ 501.4648 & -2.2583 \\ 501.2207 & -2.40479 \\ 501.3428 & -2.53906 \\ 500.8545 & -2.6123 \\ 603.6377 & -3.43018 \\ 602.9053 & -3.59497 \\ 603.2715 & -4.26636 \\ 602.6611 & -4.5166 \\ 701.416 & -5.65796\end{array}$

HEADERBANKMDT01

Recording Current - Potential Curves stainless steel wire 2 and ss bracket A:ISSC2.DAT $2 / 8 / 00$

O'Leary

ss wire 2 and ss bracket $.9 \% \mathrm{NaCl}$

SCE (sat)

242

0.732422

0.7294

Wenking MP 95

38

60

(Startpotential)

(Endpotential)

1

0

Extra9

Extra8

Extra7

Extra6

Extra5

Extra4 


$\begin{aligned} \text { Extra3 } & \\ \text { Extra2 } & \\ \text { Messdaten: } & \text { E [mV], I [mA] } \\ 0.366211 & -0.04883 \\ 0.610352 & -0.05493 \\ 0.732422 & -0.04272 \\ 0.854492 & -0.03662 \\ 0.976563 & -0.04272 \\ 13.91602 & -0.04272 \\ 100.4639 & -0.05493 \\ 100.4639 & -0.06714 \\ 100.4639 & -0.09155 \\ 100.2197 & -0.09155 \\ 200.1953 & -0.14648 \\ 200.3174 & -0.50659 \\ 200.5615 & -0.67139 \\ 200.8057 & -0.73853 \\ 200.5615 & -0.82397 \\ 200.1953 & -0.82397 \\ 300.293 & -1.48315 \\ 300.0488 & -1.66016 \\ 300.293 & -1.79443 \\ 300.415 & -1.93481 \\ 299.9268 & -1.9043 \\ 404.6631 & -1.23901 \\ 405.3955 & -0.76904 \\ 404.7852 & -0.73242 \\ 405.1514 & -0.75684 \\ 404.6631 & -0.73242 \\ 501.8311 & -1.0376 \\ 502.1973 & -1.95313 \\ 502.4414 & -1.64795 \\ 502.1973 & -2.05688 \\ 502.3193 & -3.57056 \\ 602.417 & -4.83398 \\ 602.5391 & -4.22363 \\ 602.417 & -3.86963 \\ 602.0508 & -3.86963 \\ 601.6846 & -4.06494 \\ 601.8066 & -4.06494 \\ 702.5146 & -5.23682 \\ & \end{aligned}$

HEADERBANKMDT01

Recording Current - Potential Curves $\mathrm{NiTi}$ wire and SS bracket combo

A:INC1.DAT $2 / 8 / 00$

$\mathrm{NiTi}$ Combo

$.9 \% \mathrm{NaCl}$ 


\begin{tabular}{|c|c|}
\hline \multicolumn{2}{|l|}{ SCE (sat) } \\
\hline \multicolumn{2}{|l|}{242} \\
\hline \multicolumn{2}{|l|}{0.854492} \\
\hline \multicolumn{2}{|l|}{0.7294} \\
\hline \multicolumn{2}{|c|}{ Wenking MP 95} \\
\hline \multicolumn{2}{|l|}{42} \\
\hline \multicolumn{2}{|c|}{60} \\
\hline \multicolumn{2}{|c|}{ (Startpotential) } \\
\hline \multirow{2}{*}{\multicolumn{2}{|c|}{$\begin{array}{l}1 \\
0\end{array}$}} \\
\hline & \\
\hline \multicolumn{2}{|l|}{ Extra9 } \\
\hline \multicolumn{2}{|l|}{ Extra8 } \\
\hline \multicolumn{2}{|l|}{ Extra7 } \\
\hline \multicolumn{2}{|l|}{ Extra6 } \\
\hline \multicolumn{2}{|l|}{ Extra5 } \\
\hline \multicolumn{2}{|l|}{ Extra4 } \\
\hline \multicolumn{2}{|l|}{ Extra3 } \\
\hline \multicolumn{2}{|l|}{ Extra2 } \\
\hline \multicolumn{2}{|c|}{ Messdaten: $E$ [mV], I [mA] } \\
\hline 0.854492 & -0.04883 \\
\hline 0.244141 & -0.06104 \\
\hline 0.610352 & -0.04883 \\
\hline 0.854492 & -0.04883 \\
\hline 0.732422 & -0.03662 \\
\hline 101.9287 & -0.04272 \\
\hline 102.1729 & -0.04883 \\
\hline 101.6846 & -0.05493 \\
\hline 101.4404 & -0.04883 \\
\hline 102.0508 & -0.05493 \\
\hline 200.9277 & -0.13428 \\
\hline 201.2939 & -0.26245 \\
\hline 200.9277 & -0.40894 \\
\hline 200.8057 & -0.49438 \\
\hline 201.0498 & -0.64087 \\
\hline 303.3447 & -1.72729 \\
\hline 303.5889 & -2.2644 \\
\hline 303.7109 & -2.56958 \\
\hline 303.9551 & -2.64282 \\
\hline 303.833 & -2.81372 \\
\hline 402.832 & -3.96118 \\
\hline 403.3203 & -4.30908 \\
\hline 403.5645 & -4.65088 \\
\hline 403.3203 & -5.26733 \\
\hline 403.5645 & -5.68848 \\
\hline 500.1221 & -7.6416 \\
\hline 498.7793 & -8.19702 \\
\hline 499.6338 & -8.88062 \\
\hline 500 & -9.34448 \\
\hline
\end{tabular}




$\begin{array}{rr}499.3896 & -9.74121 \\ 604.3701 & -11.7981 \\ 604.248 & -12.3352 \\ 604.248 & -13.1104 \\ 604.0039 & -13.5986 \\ 604.248 & -14.0381 \\ 700.0732 & -16.5649 \\ 700.0732 & -17.4988 \\ 700.0732 & -18.1824 \\ 699.707 & -19.1772 \\ 699.9512 & -19.2627 \\ 801.8799 & -22.4182 \\ 802.124 & -23.1201\end{array}$

\section{HEADERBANKMDT01}

Recording Current - Potential Curves niti wire and ss bracket 2

A:INC2.DAT $2 / 8 / 00$

O'Leary

niti wire and ss bracket 2 $.9 \% \mathrm{NaCl}$

SCE (sat)

242

0.366211

0.7294

Wenking MP 95

42

60

(Startpotential)

(Endpotential)

1

0

Extra9

Extra8

Extra7

Extra6

Extra5

Extra4

Extra3

Extra2

Messdaten: E [mV], I [mA]

$1.098633-0.03662$

$0.488281-0.01831$

$0.610352-0.02441$

$0.854492-0.04272$

$0.732422-0.02441$

$14.52637-0.04272$ 


\begin{tabular}{rr}
98.2666 & -0.03662 \\
98.87695 & -0.04272 \\
98.38867 & -0.04272 \\
98.87695 & -0.02441 \\
98.38867 & -0.03052 \\
198.7305 & -0.07935 \\
199.4629 & -0.11597 \\
200.1953 & -0.24414 \\
199.9512 & -0.44556 \\
199.585 & -0.62256 \\
303.833 & -1.72729 \\
303.833 & -2.28271 \\
303.833 & -2.58789 \\
304.0771 & -2.771 \\
304.1992 & -2.93579 \\
402.2217 & -4.09546 \\
402.4658 & -4.73022 \\
402.4658 & -5.10864 \\
402.0996 & -5.36499 \\
401.9775 & -5.5603 \\
501.9531 & -7.18994 \\
502.5635 & -7.55005 \\
501.8311 & -7.8064 \\
501.5869 & -7.93457 \\
602.2949 & -9.53979 \\
602.6611 & -9.96094 \\
602.6611 & -10.3149 \\
602.6611 & -10.5347 \\
602.6611 & -10.8398 \\
704.834 & -12.6709 \\
705.0781 & -13.5681 \\
705.3223 & -14.1052 \\
705.3223 & -16.2292 \\
705.0781 & -16.687 \\
800.415 & -18.9331 \\
800.6592 & -18.9514 \\
& \\
\hline
\end{tabular}

\section{HEADERBANKMDT01}

Recording Current - Potential Curves tma wire 1 and ss bracket

\section{A:ITC1.DAT \\ $2 / 8 / 00$}

tma wire 1 and ss bracket

$.9 \% \mathrm{NaCl}$

SCE (sat)

242

0.610352 
0.7294

Wenking MP 95

38

60

(Startpotential)

(Endpotential)

1

0

Extra9

Extra8

Extra7

Extra6

Extra5

Extra4

Extra3

Extra2

Messdaten: $E$ [mV], I [mA]

$0.976563 \quad-0.02441$

$0.610352-0.04272$

$\begin{array}{ll}1.220703 & -0.02441\end{array}$

$0.732422-0.03052$

$0.366211-0.01831$

$\begin{array}{ll}1.220703 & -0.01221\end{array}$

$102.0508-0.02441$

$102.417-0.03052$

$101.4404-0.04272$

$101.6846-0.03662$

$101.1963-0.03052$

$202.7588-0.177$

$203.125 \quad-0.36621$

$203.0029-0.50049$

$202.6367-0.59814$

$301.3916-1.19629$

$301.5137-1.9043$

$301.7578-2.30713$

$301.5137-2.63062$

$301.7578-2.79541$

$400.5127 \quad-3.8147$

$400.0244 \quad-4.14429$

$400.2686 \quad-4.3457$

$400.3906 \quad-4.5105$

$400.5127-4.62646$

$500.7324-5.81665$

$501.2207-6.10352$

$500.8545 \quad-6.25$

$500.6104-6.43921$

$500.9766-6.49414$

$602.1729-7.73315$

$602.0508-8.06885$

$601.9287-8.26416$

$602.0508-8.3252$ 


$$
\begin{array}{rr}
602.0508 & -8.5022 \\
703.3691 & -9.80835 \\
703.125 & -10.1929 \\
703.8574 & -10.3882
\end{array}
$$

HEADERBANKMDT01

Recording Current - Potential Curves tma wire 2 and ss bracket
A:ITC2.DAT
$12 / 2 / 99$

tma wire 2 and ss bracket

$.9 \% \mathrm{NaCl}$

$$
\begin{array}{r}
\text { SCE (sat) } \\
242 \\
0.976563 \\
0.7294
\end{array}
$$

Wenking MP 95

46

60

(Startpotential)

(Endpotential)

1

0

Extra9

Extra8

Extra7

Extra6

Extra5

Extra4

Extra3

Extra2

Messdaten: E [mV], I [mA]

$1.586914-0.08545$

$0.244141-0.04272$

$0.610352-0.02441$

$\begin{array}{ll}0 & -0.03662\end{array}$

$0.732422 \quad 0$

$101.4404-0.01221$

$101.4404-0.04883$

$101.5625-0.03052$

$100.9521-0.03662$

$101.4404-0.02441$

$201.1719-0.03662$

$201.2939-0.07324$

$201.6602-0.13428$

$201.6602-0.20752$

$202.0264-0.37231$ 


$\begin{array}{rr}303.4668 & -0.94604 \\ 303.4668 & -1.58691 \\ 303.4668 & -1.99585 \\ 303.3447 & -2.22778 \\ 303.7109 & -2.37427 \\ 401.4893 & -3.42407 \\ 401.6113 & -3.76587 \\ 402.0996 & -3.90625 \\ 401.7334 & -4.01611 \\ 401.8555 & -4.20532 \\ 501.9531 & -5.41382 \\ 501.8311 & -5.57861 \\ 502.3193 & -5.61523 \\ 501.4648 & -5.74341 \\ 501.9531 & -5.88379 \\ 603.6377 & -7.45239 \\ 604.126 & -8.19092 \\ 604.0039 & -8.53882 \\ 604.248 & -8.6792 \\ 604.9805 & -8.83179 \\ 702.7588 & -10.2783 \\ 701.9043 & -10.3943 \\ 702.3926 & -10.4309 \\ 702.2705 & -10.3943 \\ 703.3691 & -10.4309 \\ 805.2979 & -11.8286 \\ 805.1758 & -12.0178 \\ 803.9551 & -12.0483 \\ 804.3213 & -11.8042 \\ 803.7109 & -7.51343 \\ 901.9775 & -8.46558\end{array}$

HEADERBANKMDT01

Recording Current - Potential Curves

TMA WIRE 3 AND SS BRACKET

A:ITC3.DAT $2 / 9 / 00$

O'Leary

tma wire 3 and ss bracket $.9 \% \mathrm{NaCl}$

SCE (sat)

242

0.732422

0.7294

Wenking MP 95

36

60

(Startpotential)

(Endpotential) 
Extra9

Extra8

Extra7

Extra6

Extra5

Extra4

Extra3

Extra2

Messdaten: $E$ [mV], I [mA]

$1.342773-0.05493$

$1.220703-0.03662$

$0.976563-0.05493$

$0.12207-0.03662$

$0.610352-0.04272$

$101.4404-0.06104$

$101.6846-0.04272$

$101.6846-0.05493$

$101.6846-0.05493$

$101.8066-0.05493$

$203.3691-0.06714$

$203.7354-0.14038$

$203.3691-0.21362$

$204.1016-0.27466$

$204.1016-0.32349$

$300.9033-0.8606$

$302.002-1.5686$

$300.6592-1.82495$

$301.0254-2.13623$

$301.0254-2.30713$

$402.832 \quad-3.36914$

$402.9541-3.85742$

$402.5879-4.14429$

$402.4658-4.45557$

$402.3438-4.52271$

$502.8076 \quad-5.5603$

$503.1738-6.04858$

$503.1738-6.21948$

$502.9297-6.39038$

$503.0518-6.50024$

$573.3643 \quad-7.35474$

$601.9287-8.24585$

$601.4404-8.60596$

$601.1963-8.66089$

$601.1963-8.72803$

$700.1953-10.1318$

HEADERBANKMDT01

Recording Current - Potential Curves ss wire and ceramic bracket 


\section{A:ICERAM.DAT \\ 2/23/00}

ss wire and ceramic bracket

$.9 \% \mathrm{NaCl}$

SCE (sat) 242

0.610352

0.7294

Wenking MP 95

83

60

(Startpotential)

(Endpotential)

1

0

$\begin{array}{ll}\text { Extra9 } & \\ \text { Extra8 } & \\ \text { Extra7 } & \\ \text { Extra6 } & \\ \text { Extra5 } & \\ \text { Extra4 } & \\ \text { Extra3 } & \\ \text { Extra2 } & \\ \text { Messdaten: } & \text { E [mV], I [mA } \\ 0.366211 & -0.05493 \\ 0.244141 & -0.03662 \\ 0.488281 & -0.02441 \\ -0.85449 & -0.01831 \\ 0.610352 & -0.01221 \\ 101.0742 & -0.04883 \\ 103.0273 & -0.03662 \\ 102.0508 & -0.01831 \\ 102.6611 & 0.024414 \\ 101.5625 & 0.012207 \\ 199.0967 & \\ 199.2188 & -0.04272 \\ 198.8525 & 0.006104 \\ 199.8291 & -0.07935 \\ 197.1436 & -0.06104 \\ 303.7109 & -0.10376 \\ 302.8564 & -0.13428 \\ 303.7109 & -0.04883 \\ 303.2227 & -0.09766 \\ 303.3447 & -0.10376 \\ 403.6865 & -0.13428 \\ 402.4658 & -0.24414 \\ 401.123 & -0.28687 \\ 401.6113 & -0.48218 \\ & \end{array}$




$\begin{array}{rr}401.8555 & -0.5127 \\ 503.418 & -0.55542 \\ 503.418 & -0.72632 \\ 503.1738 & -0.75684 \\ 502.5635 & -0.84229 \\ 503.1738 & -1.01318 \\ 502.4414 & -1.0376 \\ 602.0508 & -2.4231 \\ 601.5625 & -3.69263 \\ 601.5625 & -4.32739 \\ 601.4404 & -5.29785 \\ 702.0264 & -7.21436 \\ 702.3926 & -9.28955 \\ 701.9043 & -10.4492 \\ 701.0498 & -11.6821 \\ 702.1484 & -11.853 \\ 804.9316 & -14.5874 \\ 804.8096 & -16.3269 \\ 804.5654 & -17.8345 \\ 804.1992 & -17.8406 \\ 804.4434 & -18.4631 \\ 899.6582 & -20.7825 \\ 899.292 & -22.6196 \\ 898.9258 & -22.4487 \\ 899.292 & -23.2788 \\ 899.4141 & -23.6938 \\ 1000.732 & -25.7813 \\ 1000.366 & -25.3845 \\ 1000.244 & -25.3357 \\ 1000.732 & -25.592 \\ 1001.343 & -26.6418 \\ 1000.732 & -26.9653 \\ 1098.267 & -28.6987 \\ 1098.389 & -28.9124 \\ 1098.511 & -28.8452 \\ 1099.121 & -28.833 \\ 1196.777 & -30.1331 \\ 1195.557 & -30.3528 \\ 1196.411 & -30.0659 \\ 1195.923 & -30.3284 \\ 1196.777 & -30.2368 \\ 1298.462 & -31.0059 \\ 1299.316 & -31.2134 \\ 1298.828 & -31.073 \\ 1395.63 & -31.8359 \\ 1397.095 & -31.8726 \\ 1499.634 & -32.3608 \\ 1498.413 & -32.605 \\ 1498.901 & -32.8674 \\ 1497.314 & -32.7637 \\ 1601.318 & -33.1665\end{array}$




$\begin{array}{lr}1601.074 & -29.6997 \\ 1699.341 & -30.4749 \\ 1698.486 & -30.481 \\ 1798.706 & -30.9143 \\ 1799.194 & -30.4749 \\ 1902.588 & -30.9998 \\ 1902.588 & -31.3416 \\ 1990.723 & -0.03052\end{array}$

\section{HEADERBANKMDT01}

Recording Current - Potential Curves gold wire

A:IGOLDW.DAT

$12 / 2 / 99$

gold wire

$.9 \% \mathrm{NaCl}$

SCE (sat)

242

1.098633

0.384

Wenking MP 95

101

60

(Startpotential)

(Endpotential)

1

0

Extra9

Extra8

Extra7

Extra6

Extra5

Extra4

Extra3

Extra2

Messdaten: E [mV], I [mA]

$1.098633-0.05493$

$1.098633-0.04883$

$1.098633-0.05493$

$0.976563-0.04883$

$1.220703-0.05493$

$100.5859-0.06104$

$100.4639-0.04883$

$100.4639-0.05493$

$100.5859-0.05493$

$100.4639-0.06104$

$100.3418-0.05493$ 


$\begin{array}{rr}100.4639 & -0.05493 \\ 201.416 & -0.05493 \\ 201.416 & -0.06104 \\ 201.416 & -0.05493 \\ 303.7109 & -0.05493 \\ 303.7109 & -0.06104 \\ 303.4668 & -0.06104 \\ 303.3447 & -0.06104 \\ 303.4668 & -0.06104 \\ 404.1748 & -0.06104 \\ 404.0527 & -0.06104 \\ 404.0527 & -0.06104 \\ 404.0527 & -0.06104 \\ 404.0527 & -0.06104 \\ 502.9297 & -0.06104 \\ 502.8076 & -0.06104 \\ 502.9297 & -0.06104 \\ 502.8076 & -0.06104 \\ 502.8076 & -0.06104 \\ 605.4688 & -0.06104 \\ 605.4688 & -0.06104 \\ 605.4688 & -0.06104 \\ 605.4688 & -0.06104 \\ 605.4688 & -0.06104 \\ 700.6836 & -0.06104 \\ 700.6836 & -0.06104 \\ 700.6836 & -0.06104 \\ 700.6836 & -0.06104 \\ 800.7813 & -0.06104 \\ 800.7813 & -0.06104 \\ 800.7813 & -0.06104 \\ 801.0254 & -0.06104 \\ 800.6592 & -0.06104 \\ 642.0898 & -0.05493 \\ 645.2637 & -0.04883 \\ 746.9482 & -0.04883 \\ 750.1221 & -0.01831 \\ 747.0703 & -0.04883 \\ 743.5303 & -0.04883 \\ 844.3604 & -0.01831 \\ 837.1582 & -0.03662 \\ 1000.122 & -0.06104 \\ 999.7559 & -0.06104 \\ 1000.244 & -0.06104 \\ 1097.656 & -0.06104 \\ 1097.778 & -0.04883 \\ 1097.9 & -0.04883 \\ 1097.9 & -0.05493 \\ 1097.778 & -0.05493 \\ 1198.975 & -0.05493 \\ 1198.975 & -0.05493\end{array}$




$\begin{aligned} 1198.853 & -0.04883 \\ 1198.853 & -0.04883 \\ 1198.853 & -0.04883 \\ 1298.462 & -0.04272 \\ 1298.584 & -0.05493 \\ 1298.096 & -0.05493 \\ 1298.34 & -0.05493 \\ 1298.706 & -0.05493 \\ 1397.583 & -0.05493 \\ 1397.583 & -0.04883 \\ 1397.339 & -0.06104 \\ 1397.705 & -0.05493 \\ 1397.705 & -0.05493 \\ 1500.244 & -0.04883 \\ 1500.244 & -0.04272 \\ 1500.366 & -0.04883 \\ 1500.244 & -0.06104 \\ 1500.244 & -0.04272 \\ 1595.703 & -0.04883 \\ 1595.581 & -0.05493 \\ 1595.459 & -0.05493 \\ 1595.947 & -0.06104 \\ 1595.459 & -0.06104 \\ 1695.435 & -0.05493 \\ 1695.557 & -0.05493 \\ 1695.557 & -0.05493 \\ 1695.557 & -0.06104 \\ 1695.557 & -0.04883 \\ 1795.654 & -0.06104 \\ 1795.654 & -0.04272 \\ 1795.654 & -0.03052 \\ 1795.776 & -0.04883 \\ 1795.776 & -0.06104 \\ 1897.339 & -0.04883 \\ 1896.973 & -0.04883 \\ 1896.973 & -0.04883 \\ 1896.973 & -0.04272 \\ 1897.217 & -0.04883 \\ 1997.803 & -0.04883\end{aligned}$

HEADERBANKMDT01

Recording Current - Potential Curves gold wire scratched

A:ISCGOLDW.DAT

$2 / 23 / 00$

gold wire scratched

$.9 \% \mathrm{NaCl}$ 


\begin{tabular}{|c|c|}
\hline \multicolumn{2}{|l|}{ SCE (sat) } \\
\hline \multicolumn{2}{|l|}{242} \\
\hline \multicolumn{2}{|l|}{0.854492} \\
\hline \multicolumn{2}{|l|}{0.384} \\
\hline \multicolumn{2}{|c|}{ Wenking MP 95} \\
\hline \multicolumn{2}{|l|}{95} \\
\hline \multirow{2}{*}{\multicolumn{2}{|c|}{$\begin{array}{c}60 \\
\text { (Startpotential) }\end{array}$}} \\
\hline & \\
\hline \multicolumn{2}{|c|}{ (Endpotential) } \\
\hline \multicolumn{2}{|c|}{$\begin{array}{l}1 \\
0\end{array}$} \\
\hline \multicolumn{2}{|l|}{ Extra9 } \\
\hline \multicolumn{2}{|l|}{ Extra8 } \\
\hline \multicolumn{2}{|l|}{ Extra7 } \\
\hline \multicolumn{2}{|l|}{ Extra6 } \\
\hline \multicolumn{2}{|l|}{ Extra5 } \\
\hline \multicolumn{2}{|l|}{ Extra4 } \\
\hline \multicolumn{2}{|l|}{ Extra3 } \\
\hline \multicolumn{2}{|l|}{ Extra2 } \\
\hline \multicolumn{2}{|c|}{ Messdaten: $E[\mathrm{mV}], \mathrm{I}[\mathrm{mA}]$} \\
\hline 1.098633 & -0.05493 \\
\hline 1.098633 & -0.04883 \\
\hline 0.976563 & -0.04272 \\
\hline 1.098633 & -0.04272 \\
\hline 0.976563 & -0.05493 \\
\hline 100.3418 & -0.04272 \\
\hline 100.4639 & -0.05493 \\
\hline 100.3418 & -0.05493 \\
\hline 100.5859 & -0.06104 \\
\hline 100.3418 & -0.04883 \\
\hline 201.416 & -0.05493 \\
\hline 201.416 & -0.06104 \\
\hline 201.416 & -0.06104 \\
\hline 201.416 & -0.04883 \\
\hline 201.416 & -0.04883 \\
\hline 301.5137 & -0.04883 \\
\hline 301.5137 & -0.04883 \\
\hline 301.6357 & -0.04883 \\
\hline 301.5137 & -0.06104 \\
\hline 301.5137 & -0.04883 \\
\hline 404.0527 & -0.06104 \\
\hline 404.1748 & -0.04883 \\
\hline 404.0527 & -0.04883 \\
\hline 404.0527 & -0.06104 \\
\hline 404.0527 & -0.05493 \\
\hline 502.9297 & -0.04883 \\
\hline 503.2959 & -0.06104 \\
\hline 503.0518 & -0.04883 \\
\hline 503.0518 & -0.05493 \\
\hline 503.0518 & -0.04883 \\
\hline 603.0273 & -0.04272 \\
\hline
\end{tabular}




$\begin{array}{rr}602.6611 & -0.04272 \\ 602.6611 & -0.03662 \\ 602.9053 & -0.04883 \\ 603.0273 & -0.04883 \\ 702.7588 & -0.04883 \\ 703.125 & -0.04883 \\ 703.125 & -0.03052 \\ 703.0029 & -0.04272 \\ 703.125 & -0.04883 \\ 801.6357 & -0.03662 \\ 802.002 & -0.06104 \\ 801.7578 & -0.05493 \\ 801.8799 & -0.05493 \\ 801.7578 & -0.04883 \\ 899.1699 & -0.05493 \\ 898.8037 & -0.05493 \\ 898.9258 & -0.04272 \\ 999.3896 & -0.05493 \\ 999.7559 & -0.05493 \\ 999.6338 & -0.06104 \\ 1100.098 & -0.04883 \\ 1100.22 & -0.05493 \\ 1100.342 & -0.04883 \\ 1099.854 & -0.05493 \\ 1099.854 & -0.03662 \\ 1100.464 & -0.05493 \\ 1202.393 & -0.04883 \\ 1202.393 & -0.06104 \\ 1202.393 & -0.04272 \\ 1202.393 & -0.04272 \\ 1299.194 & -0.04883 \\ 1298.95 & -0.04272 \\ 1299.683 & -0.04883 \\ 1299.316 & -0.06104 \\ 1399.536 & -0.05493 \\ 1399.17 & -0.05493 \\ 1399.292 & -0.06104 \\ 1399.17 & -0.05493 \\ 1399.292 & -0.04883 \\ 1495.361 & -0.04272 \\ 1495.361 & -0.04272 \\ 1495.483 & -0.03052 \\ 1495.361 & -0.05493 \\ 1495.361 & -0.05493 \\ 1598.755 & -0.04272 \\ 1599.121 & -0.04883 \\ 1599.121 & -0.04883 \\ 1598.877 & -0.04883 \\ 1598.877 & -0.04883 \\ 1696.533 & -0.04272 \\ 1696.533 & -0.04272 \\ & \end{array}$




$\begin{array}{ll}1696.411 & -0.04883 \\ 1696.411 & -0.04883 \\ 1696.655 & -0.03662 \\ 1796.997 & -0.04883 \\ 1797.119 & -0.04272 \\ 1797.119 & -0.03662 \\ 1796.997 & -0.04883 \\ 1796.997 & -0.04272 \\ 1899.414 & -0.03662 \\ 1899.414 & -0.04883 \\ 1899.414 & -0.04883 \\ 2001.465 & -0.03662 \\ 2001.709 & -0.04883\end{array}$

HEADERBANKMDT01

Recording Current - Potential Curves scratched gold wire 2

A:ISGW2.DAT

$2 / 24 / 00$

scratched gold wire 2

$.9 \% \mathrm{NaCl}$

SCE (sat)

242

0.366211

0.384

Wenking MP 95

76

60

(Startpotential)

(Endpotential)

1

0

Extra9

Extra8

Extra7

Extra6

Extra5

Extra4

Extra3

Extra2

Messdaten: E [mV], I [mA]

$0.244141-0.04883$

$0.12207-0.02441$

$0.366211-0.01831$

$0.244141-0.04272$

$0.12207-0.02441$

$102.9053-0.03662$ 


$\begin{array}{rr}101.0742 & -0.01831 \\ 101.4404 & -0.01221 \\ 102.9053 & -0.03052 \\ 101.9287 & -0.02441 \\ 201.9043 & -0.03052 \\ 202.1484 & -0.04883 \\ 201.5381 & -0.04272 \\ 202.1484 & -0.04883 \\ 201.7822 & -0.09766 \\ 304.4434 & -0.0061 \\ 304.0771 & 0.006104 \\ 304.5654 & -0.03662 \\ 304.4434 & -0.0061 \\ 303.4668 & -0.04272 \\ 401.7334 & -0.02441 \\ 401.3672 & -0.01221 \\ 401.123 & -0.04272 \\ 401.001 & -0.09766 \\ 501.709 & -0.32959 \\ 501.8311 & -1.00708 \\ 500.4883 & -1.34888 \\ 503.418 & -1.3855 \\ 501.8311 & -1.59302 \\ 603.3936 & -2.38647 \\ 603.2715 & -3.09448 \\ 603.7598 & -3.58887 \\ 603.8818 & -3.76587 \\ 702.5146 & -4.88281 \\ 702.8809 & -5.18799 \\ 702.8809 & -5.50537 \\ 703.6133 & -5.76782 \\ 703.0029 & -5.74341 \\ 800.1709 & -6.95801 \\ 800.293 & -7.4646 \\ 801.0254 & -7.71484 \\ 901.4893 & -9.26514 \\ 901.4893 & -9.14307 \\ 902.0996 & -9.375 \\ 901.4893 & -9.8938 \\ 1002.197 & -11.1633 \\ 1002.808 & -12.0544 \\ 1004.028 & -23.2117 \\ 1098.999 & -24.4385 \\ 1099.731 & -25.7446 \\ 1098.145 & -27.1484 \\ 1097.9 & -26.8005 \\ 1199.097 & -28.5217 \\ 1198.975 & -29.7852 \\ 1199.829 & -29.6387 \\ 1198.608 & -29.5959 \\ 1200.073 & -29.5715\end{array}$




$\begin{array}{rr}1298.096 & -30.4993 \\ 1298.706 & -30.5054 \\ 1298.95 & -30.7373 \\ 1396.362 & -31.3538 \\ 1396.362 & -31.5613 \\ 1395.874 & -31.6528 \\ 1497.192 & -31.9824 \\ 1496.948 & -33.1482 \\ 1496.948 & -32.8369 \\ 1594.971 & -33.313 \\ 1594.116 & -32.7881 \\ 1595.337 & -30.0354 \\ 1699.707 & -32.2144 \\ 1699.219 & -32.7698 \\ 1796.387 & -32.8247 \\ 1795.532 & -32.5928 \\ 1898.071 & -33.5083 \\ 1897.461 & -33.4534 \\ 2000.732 & -33.3496\end{array}$


Name:

Date of Birth:

Place of Birth:

Hometown:

\section{Education}

$1997-2000$

$1993-1997$

$1987-1991$

Memberships

Honors/Awards

Future Plans
Brian Costello O'Leary

July 10, 1969

Royal Oak, Michigan

Columbia, South Carolina

West Virginia University

School of Dentistry

Department of Orthodontics

Morgantown, West Virginia

Master of Science

Medical University of South Carolina

College of Dental Medicine

Charleston, South Carolina

Doctor of Dental Medicine

Virginia Polytechnic Institute

College of Engineering

Blacksburg, Virginia

Bachelor of Science

American Association of Orthodontists American Dental Association

Academy of General Dentistry

Southern Association of Orthodontists

South Carolina Dental Association

Outstanding General Dentistry Award

Medical University of South Carolina

Service and Leadership Award

Carolina Children's Charity

Outstanding Service Award

Medical University of South Carolina

Dean's List 1993, 1994, 1995, 1996

Orthodontic Private Practice

Columbia, SC 